\title{
Oomycota (Straminipila) da Reserva Biológica de Paranapiacaba, Santo André, SP, Brasil ${ }^{1}$
}

\author{
Alexandra Lenk Gomes² e Carmen Lidia Amorim Pires-Zottarelli ${ }^{2,3}$
}

Recebido em 23/11/2006. Aceito em 18/06/2007

\begin{abstract}
RESUMO - (Oomycota (Straminipila) da Reserva Biológica de Paranapiacaba, Santo André, SP, Brasil). Durante o período de novembro/2003 a novembro/2004, coletas trimestrais de amostras de água e solo foram realizadas na Reserva Biológica de Paranapiacaba, importante fragmento de Mata Atlântica localizado no estado de São Paulo, para estudo da diversidade de oomicetos. Para o isolamento destes organismos, as amostras foram tratadas pelo método de iscagem, que resultou na identificação de 35 espécies, das quais uma pertence a Leptomitales, quatro a Peronosporales, duas a Rhipidiales, e 28 a Saprolegniales, sendo descritas, comentadas e ilustradas neste trabalho as de ocorrência relatada no Brasil, das quais três são citadas pela primeira vez para o estado de São Paulo, Leptolegnia eccentrica Coker \& Matthews, Pythiopsis humphreyana Coker e Pythiopsis irregularis Seymour, e 20 para a Reserva.
\end{abstract}

Palavras-chave: diversidade, fungos zoospóricos, Brasil, Mata Atlântica, oomicetos

\begin{abstract}
Oomycota (Straminipila) from the Paranapiacaba Biological Reserve, Santo André, São Paulo State, Brazil). From November/2003 to November/2004, water and soil samples were collected every three months in the Paranapiacaba Biological Reserve, an important fragment of Brazilian Atlantic rain forest, to study Oomycota diversity. To isolate these organisms, the samples were treated by the baiting technique, which resulted in the identification of 35 species: one belongs to Leptomitales, four to Peronosporales, two to Rhipidiales and 28 to Saprolegniales; in this paper we describe and illustrate, with comments, the species already mentioned for Brazil. Three are cited for the first time for São Paulo state, Leptolegnia eccentrica Coker \& Matthews, Pythiopsis humphreyana Coker and Pythiopsis irregularis Seymour, and 20 for this area.
\end{abstract}

Key words: diversity, zoosporic fungi, Brazil, Atlantic rain forest, Oomycetes

\section{Introdução}

O filo Oomycota, inserido no Reino Straminipila, possui apenas uma classe, Oomycetes, com 12 ordens, 27 famílias, 92 gêneros e 808 espécies (Kirk et al. 2001). Os seus representantes estão presentes nos ecossistemas aquáticos, marinhos e continentais, e terrestres, onde vivem saprobiamente em detritos vegetais e animais, podendo ser parasitas de algas, peixes, larvas de mosquitos, rotíferos, plantas, mamíferos, incluindo o homem. São organismos unicelulares, com talo holocárpico, ou miceliais, com talo eucárpico e hifas cenocíticas. A reprodução assexuada se dá por meio de zoósporos biflagelados e, a sexuada, pelo contato de gametângios diferenciados ou pela copulação de gametângios, onde casos de partenogênese são relatados (Alexopoulos et al. 1996).

Estudos com este grupo de organismos no Brasil ainda são poucos, se considerarmos que conhecemos somente $22 \%$ dos táxons já relatados para o mundo (C.L.A. Pires-Zottarelli, comunicação pessoal). Em áreas de Mata Atlântica, embora seja o ecossistema mais estudado, a carência de informações ainda é grande (Milanez et al. 1994, Schoenlein-Crusius et al. 2006). Na Reserva Biológica de Paranapiacaba, importante fragmento de Mata Atlântica localizado no Estado de São Paulo, os estudos tiveram início com Rogers et al. (1970) por meio de coletas esporádicas para levantamento de fungos zoospóricos. Depois de vários anos, foram realizados outros estudos com enfoque ecológico (Schoenlein-Crusius et al. 1992; Pires-Zottarelli et al. 1993; Antunes et al. 1993; Schoenlein-Crusius \& Milanez 1998; SchoenleinCrusius et al. 1998, 1999). Entretanto, o conhecimento da diversidade de Oomycota na Reserva ainda era inexpressivo, com apenas 13 táxons e oito espécies conhecidas. O presente trabalho contribui, de forma significativa, para a ampliação do conhecimento da diversidade dos oomicetos da Reserva.

\footnotetext{
1 Parte da Dissertação de Mestrado da primeira Autora

2 Instituto de Botânica de São Paulo, Seção de Micologia e Liquenologia, C. Postal 3005, 01061-970, São Paulo, SP, Brasil

3 Autor para correspondência: zottarelli@uol.com.br
} 


\section{Material e métodos}

Coletas trimestrais de amostras de água e solo (40 de água e 40 de solo) foram realizadas de novembro/2003 a novembro/2004 na Reserva Biológica

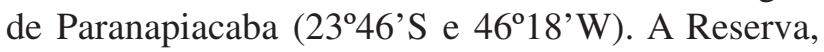
com 336 ha, está situada no Município de Santo André a 50 km da cidade de São Paulo, localizando-se próxima ao complexo da Serra do Mar. Sob administração do Instituto de Botânica de São Paulo, encontra-se bem preservada, levando-se em consideração sua proximidade com o pólo industrial de Cubatão (Secretaria Estadual do Meio Ambiente 2000).

Para obtenção dos oomicetos, a técnica descrita em Milanez (1989) foi utilizada, a qual consiste na iscagem dos fungos por meio da utilização de diferentes substratos, em laboratório e em campo. Após iscagem e isolamento dos táxons de oomicetos, estes foram purificados em meios específicos, sendo utilizado $\mathrm{MP}_{5}$ (Beneke \& Rogers 1962) para Saprolegniaceae e CMA com antibióticos (penicilina, estreptomicina e vancomicina) (Carvalho \& Milanez 1989, modificado) para Pythiaceae. Para identificação dos isolados, ao nível específico, medidas (20) das estruturas assexuais (zoosporângios e zoósporos) e sexuais (oogônios, oósporos e esporos de resistência) foram realizadas. Os espécimes identificados, por meio de literatura específica, foram preservados em frascos "Wheaton" com água destilada esterilizada (Milanez 1989), pelo método de Castellani (Figueiredo \& Pimentel 1975) e/ou em lâminas semi-permanentes e incorporados aos acervos do Instituto de Botânica de São Paulo (Coleção de Culturas de Fungos - SPC e Herbário do Instituto de Botânica - SP).

\section{Resultados e discussão}

De um total de 175 isolamentos, foram identificadas 35 espécies, das quais 28 , com ocorrência anteriormente relatada no Brasil são descritas, comentadas e ilustradas (Tab. 1). Os táxons mencionados pela primeira vez para o país constam em Gomes \& Pires-Zottarelli (2006).

\section{FILO OOMYCOTA}

\section{LAGENIDIALES}

\section{OLPIDIOPSIDACEAE}

Olpidiopsis saprolegniae var. saprolegniae (Braun) Cornu, Ann. Sci. Nat. Bot. Ser V, 15: 145. 1872.

Fig. 1-2
Talo holocárpico, endobiótico. Zoosporângios lisos, esféricos, 17,5-22,5 um diâm. ou ovóides, 22,5-32,5× 27,5-31,25 $\mu \mathrm{m}$. Liberação dos zoósporos por meio de tubo de descarga único, persistente. Zoósporos não observados. Esporos de resistência castanhos, esféricos, com ornamentações espinhosas, 27,5-37,5 um diâm.; célula companheira única, lisa, hialina.

Material examinado: BRASIL. São Paulo: Santo André, Reserva Biológica de Paranapiacaba, amostras de água e solo, em Saprolegnia sp., 2346'78's e $46^{\circ} 18^{\prime} 55^{\prime \prime} \mathrm{W}$ e $23^{\circ} 46^{\prime} 52^{\prime \prime} \mathrm{S}$ e $46^{\circ} 18^{\prime} 77^{\prime \prime} \mathrm{W}, 20 / \mathrm{XI} / 2003$, A.L. Gomes.

Os isolados estudados apresentaram zoosporângios e esporos de resistência menores do que os citados por Sparrow (1960), que descreve zoosporângios esféricos, ovóides ou elipsoidais com até 150 um diâm., com os elipsoidais normalmente de 45-50×3-36 $\mu \mathrm{m}$, e esporos de resistência de 47-107 $\mu$ m diâm. A preparação de lâmina semi-permanente não se mostrou eficiente para preservação dos espécimes. A espécie foi isolada pela primeira vez no Brasil por Beneke \& Rogers (1962) de amostras de água da Universidade Federal de Viçosa, Minas Gerais. Esta é a primeira citação para a Reserva.

\section{PERONOSPORALES}

\section{PYTHIACEAE}

Phytophthora undulata (H.E. Petersen) M.W. Dick, Mycotaxon 35(2): 449. 1989.

Fig. 3-7

Colônia em semente de sorgo. Zoosporângios elipsoidais ou irregulares, (25-)40-77,5(-115)× (15-)25-30(-32,5) $\mu \mathrm{m}$; com proliferação interna. Zoósporos encistados de $10 \mu \mathrm{m}$ diâm. Clamidósporos âmbar, esféricos, (22,5-)30-62,5(-67,5) um diâm. Estruturas sexuadas ausentes.

Material examinado: BRASIL. São Paulo: Santo André, Reserva Biológica de Paranapiacaba, amostras

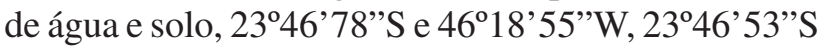

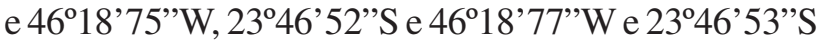
e 46² $18^{\prime} 75^{\prime \prime} \mathrm{W}, 20 / \mathrm{XI} / 2003,26 / \mathrm{II} / 2004,18 / \mathrm{XI} / 2004$, A.L. Gomes (SPC 1960, 1963).

Grande variação de formas de zoosporângios nos espécimes foi observada, fato também relatado por Goldie-Smith (1952). As características dos espécimes concordam com a descrição de Plaats-Niterink (1981) e Baptista et al. (2004); no entanto, Dick (1989) coloca Pythium undulatum como sinonímia de Phytophthora undulata, o que é aceito no presente estudo. No Brasil, 
Tabela 1. Táxons de Oomycota isolados da Reserva Biológica de Paranapiacaba, SP, Brasil de novembro/2003 a novembro/2004. (A = Água; $\mathrm{S}=$ Solo).

\begin{tabular}{|c|c|c|c|c|c|}
\hline Táxons/Meses & nov/2003 & $\mathrm{fev} / 2004$ & $\mathrm{mai} / 2004$ & ago/2004 & nov/2004 \\
\hline \multicolumn{6}{|l|}{ REINO STRAMINIPILA } \\
\hline \multicolumn{6}{|l|}{ FILO OOMYCOTA } \\
\hline \multicolumn{6}{|l|}{ LAGENIDIALES } \\
\hline \multicolumn{6}{|l|}{ OLPIDIOPSIDACEAE } \\
\hline Olpidiopsis saprolegniae var. saprolegniae (Braun) Cornu * & $\mathrm{A} / \mathrm{S}$ & & & & \\
\hline \multicolumn{6}{|l|}{ PERONOSPORALES } \\
\hline \multicolumn{6}{|l|}{ PYTHIACEAE } \\
\hline Pythiogeton ramosum Minden * & $\mathrm{S}$ & & & & \\
\hline Pythium helicandrum Drechsler $* * *$ & $\mathrm{~S}$ & $\mathrm{~S}$ & & & $\mathrm{~S}$ \\
\hline Py. torulosum Coker \& Patterson * & & & A & & \\
\hline $\begin{array}{l}\text { Phytophthora undulata (H.E. Petersen) M.W. Dick } \\
\quad(=\text { Py. undulatum H.E. Petersen)* }\end{array}$ & $\mathrm{A} / \mathrm{S}$ & A & & & $\mathrm{S}$ \\
\hline \multicolumn{6}{|l|}{ RHIPIDIALES } \\
\hline \multicolumn{6}{|l|}{ RHIPIDIACEAE } \\
\hline Rhipidium interruptum Cornu* & & & A & & \\
\hline Sapromyces androgynus Thaxter * & A & & A & A & A \\
\hline \multicolumn{6}{|l|}{ SAPROLEGNIALES } \\
\hline \multicolumn{6}{|l|}{ LEPTOLEGNIELLACEAE } \\
\hline Leptolegniella exogena Karling *** & & & $\mathrm{S}$ & & \\
\hline L. keratinophila Huneycutt $*$ & $\mathrm{~S}$ & & $\mathrm{~S}$ & & \\
\hline \multicolumn{6}{|l|}{ SAPROLEGNIACEAE } \\
\hline Achlya apiculata de Bary & & & & $\mathrm{S}$ & \\
\hline A. bisexualis Coker \& A. Couch & & $\mathrm{S}$ & & & A \\
\hline A. cambrica (Trow) Johnson * & $\mathrm{S}$ & & & & \\
\hline A. flagellata Coker & $\mathrm{A} / \mathrm{S}$ & $\mathrm{A} / \mathrm{S}$ & & A & A \\
\hline A. klebsiana Pieters * & & $\mathrm{A} / \mathrm{S}$ & & & \\
\hline A. orion Coker \& Couch & & & A & & \\
\hline A. prolifera C.G. Nees * & & A & A & & $\mathrm{A} / \mathrm{S}$ \\
\hline A. radiosa Maurizio & A & $\mathrm{A} / \mathrm{S}$ & $\mathrm{A} / \mathrm{S}$ & $\mathrm{A} / \mathrm{S}$ & \\
\hline A. subterranea Coker \& Braxton * & & $\mathrm{S}$ & $\mathrm{A} / \mathrm{S}$ & $\mathrm{A} / \mathrm{S}$ & $\mathrm{S}$ \\
\hline A. treleaseana (Humphrey) Kauffman $* * *$ & & & $\mathrm{~A} / \mathrm{S}$ & & \\
\hline Aphanomyces cladogamus Drechsler* & & $\mathrm{S}$ & $\mathrm{S}$ & & \\
\hline A. irregulare Scott* & A & & & & \\
\hline A. stellatus de Bary * & $\mathrm{S}$ & & A & $\mathrm{A} / \mathrm{S}$ & \\
\hline Brevilegnia diclina Harvey * & & $\mathrm{A} / \mathrm{S}$ & & & \\
\hline B. linearis Coker \& Braxton * & & S & & & \\
\hline Dictyuchus pseudodictyon Coker \& Braxton ex Couch* & $\mathrm{A} / \mathrm{S}$ & & $\mathrm{A} / \mathrm{S}$ & $\mathrm{A} / \mathrm{S}$ & $\mathrm{A} / \mathrm{S}$ \\
\hline Geolegnia inflata Coker \& Harvey * & & & & S & \\
\hline Leptolegnia eccentrica Coker \& Matthews ** & $\mathrm{S}$ & & & & $\mathrm{S}$ \\
\hline L. subterranea Coker \& Harvey $* * *$ & & & $\mathrm{~S}$ & & \\
\hline Phragmosporangium uniseriatum Seymour*** & & & & $\mathrm{S}$ & $\mathrm{S}$ \\
\hline Pythiopsis humphreyana Coker ** & & & & & $\mathrm{S}$ \\
\hline P. irregularis Seymour ** & $\mathrm{S}$ & $\mathrm{S}$ & & & $\mathrm{S}$ \\
\hline Saprolegnia blelhamensis (Dick) Mil'ko *** & & & $\mathrm{S}$ & & \\
\hline S. diclina Humphrey * & $\mathrm{A} / \mathrm{S}$ & & A & A & \\
\hline S. subterranea (Dissman) Seymour * & & & & & $\mathrm{S}$ \\
\hline S. terrestris Cookson ex Seymour *** & $\mathrm{A} / \mathrm{S}$ & $\mathrm{A} / \mathrm{S}$ & $\mathrm{A} / \mathrm{S}$ & A & \\
\hline Total & 16 & 13 & 17 & 12 & 12 \\
\hline
\end{tabular}

* primeira citação para a Reserva; ** primeira citação para o Estado de São Paulo; *** primeira citação para o Brasil. 
a primeira citação foi de Baptista et al. (2004), como Pythium undulatum, os quais a isolaram de amostras de água e solo de áreas de cerrado do Estado de São Paulo. Esta é a primeira citação da espécie para a Reserva.

Pythiogeton ramosum Minden, Falk. Mykolog. Untersuch. Berichte 2(2): 238. 1916.

Fig. 8-9

Colônia em semente de sorgo. Zoosporângios esféricos, 27,5-42,5 $\mu \mathrm{m}$ diâm. ou piriformes, 42,5-77,5×30-42,5 $\mu \mathrm{m}$, originados das hifas em ângulo de $90^{\circ}$; proliferação interna presente. Zoósporos encistados, 7,5-10 $\mu \mathrm{m}$ diâm. Estruturas sexuadas ausentes.

Material examinado: BRASIL. São Paulo: Santo André, Reserva Biológica de Paranapiacaba, amostra de solo, 2346' $53^{\prime \prime}$ S e 46¹8'75"W, 20/XI/2003, A.L. Gomes.

O espécime estudado apresentou zoosporângios piriformes menores que os descritos por Rocha \& Pires-Zottarelli (2002), que citam de 62-192×25-37 $\mu \mathrm{m}$. A preservação do espécime não foi possível por problemas de contaminação. A espécie foi isolada pela primeira vez no Brasil por Beneke \& Rogers (1970), de detritos vegetais do Parque Nacional de Itatiaia, Rio de Janeiro (RJ). Esta é a primeira citação para a Reserva.

Pythium torulosum Coker \& Patterson, J. Elisha Mitchell Sci. Soc. 42: 247. 1927.

Fig. 10-11

Micélio presente em epiderme de cebola. Zoosporângios filamentosos inflados formando complexos torulóides. Zoósporos encistados, $8 \mu \mathrm{m}$ diâm. Oogônios laterais e intercalares, 15-22,5 ㅆm diâm., pedúnculo simples; parede oogonial lisa. Anterídios monóclinos, 1 por oogônio. Oósporos pleróticos, esféricos, 12,5-15 $\mu$ m diâm.; 1 por oogônio.

Material examinado: BRASIL. São Paulo: Santo André, Reserva Biológica de Paranapiacaba, amostra de água, 2346'52'S e 46¹8'77'W, 26/V/2004, A.L. Gomes (SP 381554).

As características dos espécimes estão de acordo com a descrição de Frezzi (1956), Plaats-Niterink (1981) e Baptista et al. (2004). As estruturas sexuadas são menores que as citadas por Pires-Zottarelli \& Milanez (1993), que descrevem oogônios esféricos com

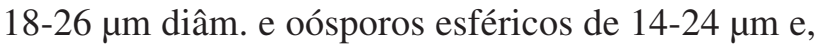
por Rocha \& Pires-Zottarelli (2002) que descrevem

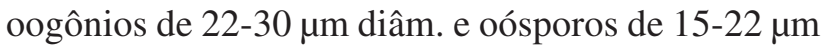

diâm. Os isolados, presentes em epiderme de cebola, foram preservados em lâminas semi-permanentes, devido à dificuldade de purificação em meio de cultura. No Brasil, a espécie foi isolada pela primeira vez por Pires-Zottarelli \& Milanez (1993), de amostras de água e solo da Represa do Lobo (Broa), localizada entre os municípios de Brotas-Itirapina (SP). Esta é a primeira citação para a Reserva.

\section{RHIPIDIALES}

\section{RHIPIDIACEAE}

Rhipidium interruptum Cornu, Bull. Soc. bot. Fr. 18: 58. 1871; in Van Tieghem, Traité de Botanique, 1024. 1884.

Fig. 12-13

Pústulas em Malus sp. Célula basal cilíndrica. Zoosporângios terminais, dispostos no ápice dos lobos da célula basal, pedicelados, clavados, 35-62,5× 15-25 $\mu \mathrm{m}$; parede lisa. Zoósporos e estruturas sexuadas não observadas.

Material examinado: BRASIL. São Paulo: Santo André, Reserva Biológica de Paranapiacaba, fruto de

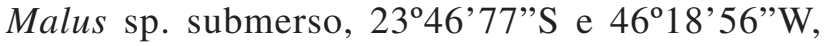
26/V/2004, A.L. Gomes (SP 381552).

Embora estruturas sexuais não tenham sido formadas, o tipo de célula basal, o tamanho e a inserção dos pedicelos e a forma dos zoosporângios caracterizam a espécie. O espécime apresentou zoosporângios menores que os descritos por Sparrow (1960), que cita zoosporângios de 40-78×18,5-47 $\mu \mathrm{m}$. Esta espécie foi isolada pela primeira vez no Brasil por Milanez \& Trufem (1984) de frutos submersos em corpos d'água do Parque Estadual das Fontes do Ipiranga, São Paulo. É a primeira citação para a Reserva.

Sapromyces androgynus Thaxter, Bot. Gaz. 21: 329. 1896.

Fig. 14-15

Pústulas em Malus sp. e Myrciaria sp. Zoosporângios fusiformes ou elipsoidais, pedicelados, terminais, 37,5-135,50×20-32,5 $\mu \mathrm{m}$. Zoósporos não observados. Oogônios lisos, pedicelados, hialinos, subglobosos, 44-75×50 $\mu \mathrm{m}$. Anterídios andróginos, raros díclinos, atracação apical, ramos e células anteridiais simples, 1-2 por oogônio; tubo de fertilização presente. Oósporos hialinos, alguns amarelados, esféricos, 27,5-45 بm diâm., 1 por oogônio.

Material examinado: BRASIL. São Paulo: Santo André, Reserva Biológica de Paranapiacaba, frutos de Malus sp. e Myrciaria sp. submersos, 2346'52"S 

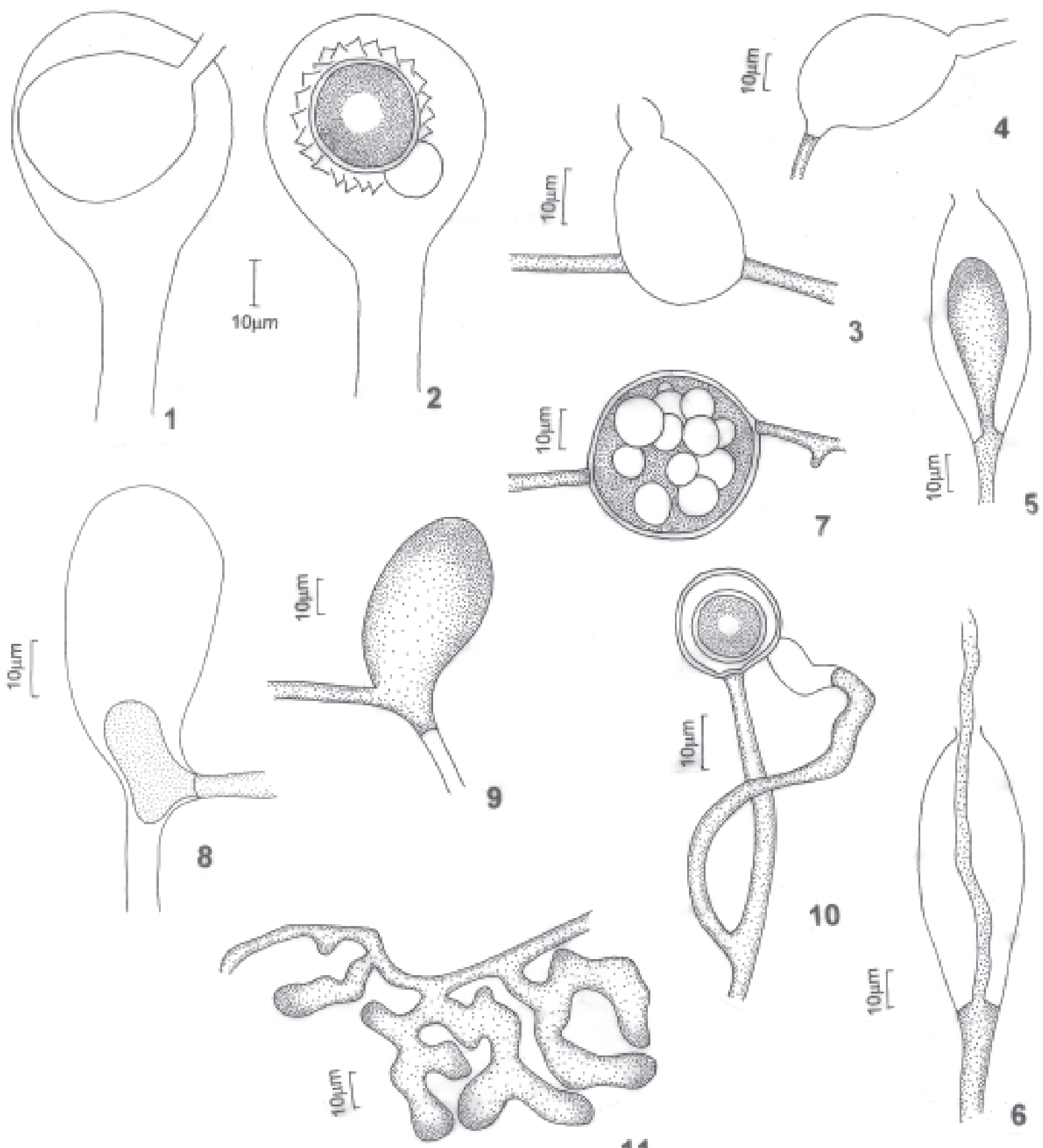

Figuras 1-12. 1-2. Olpidiopsis saprolegniae var. saprolegniae (Braun) Cornu. 1. Zoosporângio dentro de um oogônio de Saprolegnia sp. 2. Esporo de resistência com célula-companheira. 3-7. Phytophthora undulata (H.E. Petersen) M.W. Dick.. 3-4. Zoosporângios vazios. 5-6. Zoosporângios com proliferação interna. 7. Clamidósporo. 8-9. Pythiogeton ramosum Minden. 8. Zoosporângio com proliferação interna. 9. Zoosporângio em formação. 10-11. Pythium torulosum Coker \& Paterson. 10. Oogônio com anterídio monóclino. 11. Zoosporângio. 
e 46¹8'77'W, 20/XI/2003, 26/V/2004, 26/VIII/2004, 18-XI-2004, A.L. Gomes (SP 381551).

Foi observada, em alguns espécimes, a presença de anterídios díclinos, além de andróginos, fato ainda não relatado em literatura. As características dos espécimes estudados concordam com Milanez \& Trufem (1984), exceto pela presença de anterídios díclinos. Os espécimes apresentaram zoosporângios menores e oósporos maiores que os descritos por Milanez et al. (1996), que citam de 70-170×22-55 $\mu \mathrm{m}$ e 20-28 $\mu \mathrm{m}$, respectivamente. Os espécimes estudados apresentaram estruturas assexuadas e sexuadas maiores que os descritos por Sparrow (1960), o qual cita zoosporângios de 49-109×16-30 $\mu \mathrm{m}$, oogônios piriformes de 35-50×27-30 $\mu \mathrm{m}$ e oósporos de 20-26 $\mu \mathrm{m}$ diâm. A espécie foi isolada pela primeira vez no Brasil por Beneke \& Rogers (1962) de frutos submersos do Instituto de Botânica de São Paulo. Esta é a primeira citação para a Reserva.

\section{SAPROLEGNIALES}

\section{LEPTOLEGNIELLACEAE}

Leptolegniella keratinophila Huneycutt. J. Elisha Mitchell Sci. Soc. 68: 109. 1952.

Fig. 16

Micélio intramatrical, ramificado, em ecdise de cobra; hifas irregulares, ramificadas. Esporos ovais, 12-17×9-11,5 $\mu \mathrm{m}$, alguns esféricos, 12-14 $\mu \mathrm{m}$ diâm. Esporos de resistência ovais, $15-17,5 \times 10-12,5 \mu \mathrm{m}$, alguns esféricos, 12,5-14 $\mu$ m diâm.

Material examinado: BRASIL. São Paulo: Santo André, Reserva Biológica de Paranapiacaba, ecdise de cobra em amostras de solo, 2346'52"S e $46^{\circ} 18^{\prime} 77^{\prime \prime} \mathrm{W}$ e $23^{\circ} 46^{\prime} 53^{\prime \prime} \mathrm{S}$ e $46^{\circ} 18^{\prime} 75^{\prime \prime} \mathrm{W}, 20 / \mathrm{XI} / 2003$, 26/V/2004, A.L. Gomes (SP 381553).

Os espécimes estudados apresentaram esporos de resistência maiores que os descritos em literatura. Huneycutt (1952) relata esporos esféricos de 9-12 $\mu \mathrm{m}$ diâm. e ovais de $10,8-16,7 \times 6,4-10,7 \mu \mathrm{m}$ e Rocha \& Pires-Zottarelli (2002) mencionaram esporos esféricos

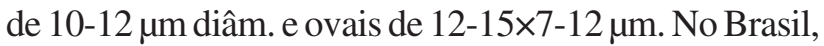
a espécie foi isolada pela primeira vez por Milanez (1970), de amostras de solo de Cruzália Paulista (SP) e Candido Mota (SP).

\section{SAPROLEGNIACEAE}

Achlya apiculata de Bary, Bot. Zeit. 46: 635. 1888.

Fig. 17-19
Colônia medindo 2,4 cm diâm. em semente de sorgo após duas semanas. Gemas presentes. Zoosporângios fusiformes, 117,5-460×17,5-40 $\mu \mathrm{m}$. Liberação dos zoósporos aclióide, zoósporos encistados 10-12 $\mu \mathrm{m}$. Oosferas maturando. Oogônios laterais, terminais ou intercalares, esféricos, 45-65 $\mu \mathrm{m}$ diâm., ou piriformes, $60-112,5 \times 50-67,5 \mu \mathrm{m}$; parede lisa ou apiculada; pedúnculo simples, pendente, retorcido e/ou curvado. Anterídios andróginos e monóclinos. Oósporos esféricos, 20-32,5 $\mu$ m diâm., subcêntricos e cêntricos; 1-10 por oogônio.

Material examinado: BRASIL. São Paulo: Santo André, Reserva Biológica de Paranapiacaba, amostra de solo, 2346' 53"'S e 46 $18^{\circ}$ '75'"W, 26/VIII/2004, A.L. Gomes (SPC 2005).

De maneira geral, as características apresentadas pelos espécimes concordam com a descrição de PiresZottarelli et al. (1996) e Johnson et al. (2002). A espécie foi primeiramente isolada no Brasil por Upadhyay (1967) de amostras de solo do município de Parnamirim (RN).

Achlya bisexualis Coker \& A. Couch, in Coker, Journal Elisha Mitchell Scientific Society 42: 207. 1927.

Fig. 20-21

Talo dióico. Colônia medindo $2,5 \mathrm{~cm}$ diâm. em semente de sorgo, após duas semanas. Gemas presentes. Zoosporângios fusiformes, 260-620× 25-70 $\mu \mathrm{m}$; renovação basipetalar e simpodial. Liberação dos zoósporos aclióide; zoósporos encistados 10-15 $\mu \mathrm{m}$ diâm. Oogônios laterais, terminais, intercalares e sésseis, esféricos, 50-62,5 $\mu$ m diâm.; parede oogonial lisa; pedúnculo simples. Anterídios estritamente díclinos, ramos simples, células anteridiais divididas, atracação lateral e apical. Oosferas maturando, algumas abortivas. Oósporos excêntricos, esféricos, 22,5-32,5 $\mu \mathrm{m}$ diâm.; 1-5 por oogônio.

Material examinado: BRASIL. São Paulo: Santo André, Reserva Biológica de Paranapiacaba, amostras de água e solo, 2346'53"'S e 46 $18^{\circ} 75^{\prime \prime}$ 'W e 2346'52"S e 46018'77'W, 26/II/2004 e 18/XI/2004, A.L. Gomes (SPC 1997).

Os oogônios dos espécimes estudados apresentaram-se menores e os zoósporos maiores que os descritos por Johnson (1956) e Johnson et al. (2002), os quais relatam de (35-)60-75(-130) $\mu \mathrm{m}$ diâm. e 9-12 $\mu \mathrm{m}$ diâm., respectivamente. Os espécimes descritos por Pires-Zottarelli et al. (1996) apresentaram estruturas maiores que as observadas, com zoosporângios de 280-980×26-70 $\mu \mathrm{m}$, oogônios de 30-130 $\mu \mathrm{m}$ diâm. e oósporos de 16-40 $\mu \mathrm{m}$. diâm. A espécie foi isolada pela primeira vez no Brasil por 

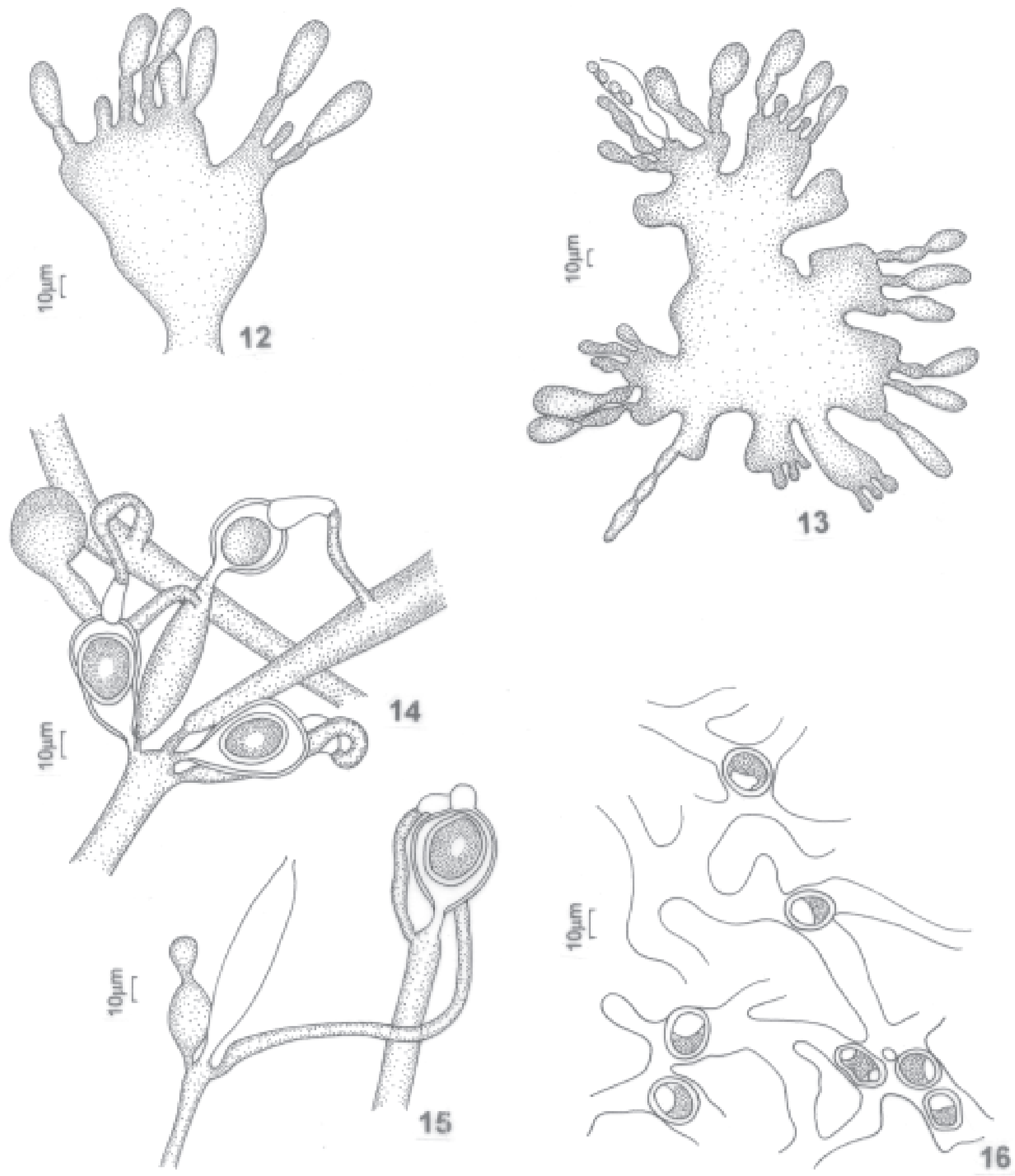

Figuras 12-16. 12-13. Rhipidium interruptum Cornu. 12. Parte da célula basal com zoosporângios. 13. Célula basal com zoosporângios. 14-15. Sapromyces androgynus Thaxter. Oogônios com anterídios díclinos e andróginos. 16. Leptolegniella keratinophila Huneycutt. Esporos de resistência formados dentro do micélio. 
Beneke \& Rogers (1962), de amostras de água do Instituto de Botânica de São Paulo e do Lago Pampulha, em Belo Horizonte (MG). Na Reserva a espécie foi isolada de folhas submersas em decomposição nos riachos (Schoenlein-Crusius et al. 1992).

Achlya cambrica (Trow) Johnson, The Genus Achlya: Morphology and Taxonomy, p. 85. 1956.

Achlya americana var. cambrica Trow 1899. Ann.

Bot., 13: 135, pls. 8-10. 1899.

Fig. 22-23

Talo monóico. Colônia medindo 2,0 cm diâm. em semente de sorgo após duas semanas. Gemas ausentes. Zoosporângios clavados, fusiformes, (100-)237,5-337,5(-437,5)×25-37,5 $\mu$ m; renovação basipetalar. Liberação dos zoósporos aclióide, zoósporos encistados, 10-12,5 ㅆm diâm. Oogônios laterais, esféricos, 32,5-45 $\mu \mathrm{m}$ diâm.; parede oogonial lisa com substância proeminente aos poros; pedúnculos retos e pendentes. Anterídios monóclinos, alguns díclinos, células e ramos anteridiais simples e divididos, atracação lateral, apical ou por projeções, 1-2 por oogônio. Oosferas maturando. Oósporos excêntricos, esféricos, 17,5-22,5 $\mu \mathrm{m}$ diâm., ou ovais, 17,5-25× 15-25 $\mu \mathrm{m} ; 1$-4 por oogônio.

Material examinado: BRASIL. São Paulo: Santo André, Reserva Biológica de Paranapiacaba, amostras de solo, 2346' $52^{\prime \prime}$ 'S e 46¹8'77'W, 20/XI/2003, A.L. Gomes (SPC 1958).

As estruturas sexuadas do espécime estudado foram menores que as descritas por Johnson (1956), que cita oogônios esféricos de (28-)50-60(-85) $\mu \mathrm{m}$ diâm. e oósporos de 15-32 $\mu$ m diâm., e Johnson et al. (2002), que citam oogônios esféricos de

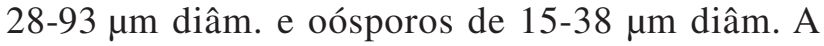
espécie foi isolada pela primeira vez no Brasil de amostras de solo da região de Cubatão (SP) (Schoenlein-Crusius et al. 2006). Esta é a primeira citação para a Reserva.

Achlya flagellata Coker, The Saprolegniaceae with notes on other water moulds: 116. 1923.

Fig. 24-25

Talo monóico. Colônia medindo 1,5-2,5 cm diâm. em semente de sorgo após duas semanas. Gemas ausentes. Zoosporângios fusiformes, 187,5-682,5× 20-50 $\mu \mathrm{m}$; renovação basipetalar. Liberação dos zoósporos aclióide, zoósporos encistados, 7,5-12,5 $\mu \mathrm{m}$ diâm. Oogônios laterais, esféricos, (27,5-)47,557,5(-70) $\mu \mathrm{m}$ diâm., ou piriformes, $57,5-75 \times 50-70 \mu \mathrm{m}$; parede oogonial lisa, com poros; pedúnculos retos, pendentes, longos. Anterídios díclinos, algumas vezes monóclinos; células e ramos anteridiais simples, atracação lateral e por projeções. Oosferas freqüentemente não maturando. Oósporos excêntricos, esféricos,

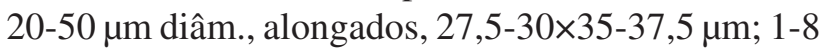
por oogônio.

Material examinado: BRASIL. São Paulo: Santo André, Reserva Biológica de Paranapiacaba, amostras

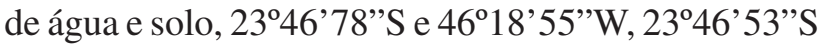
e 46 $18^{\prime} 75^{\prime \prime} \mathrm{W}, 23^{\circ} 46^{\prime} 52^{\prime \prime} \mathrm{S}$ e $46^{\circ} 18^{\prime} 77^{\prime \prime} \mathrm{W}, 23^{\circ} 46^{\prime} 52^{\prime \prime} \mathrm{S}$ e 46 $18^{\circ} 75^{\prime \prime} \mathrm{W}, 23^{\circ} 46^{\prime} 53^{\prime \prime} \mathrm{S} 46^{\circ} 18^{\prime} 69^{\prime \prime} \mathrm{W}$ e $23^{\circ} 46^{\prime} 77^{\prime \prime} \mathrm{S}$ e 46 18 '56"W, 20/XI/2003, 26/II/2004, 26/VIII/2004, 18/XI/2004, A.L. Gomes (SPC 1964).

A característica principal da espécie é a presença de anterídios díclinos ramificados e oosferas freqüentemente abortivas. Segundo Johnson et al. (2002), várias espécies de Achlya, como A. flagellata e A. klebsiana, possuem características comuns a A. debaryana, sendo então colocadas em sinonímia com a última. Maiores estudos devem ser realizados para confirmação desta proposta.

As características dos espécimes examinados estão de acordo com as descrições de Johnson (1956) e Rocha \& Pires-Zottarelli (2002). Os espécimes estudados por Pires-Zottarelli et al. (1996) apresentaram zoosporângios maiores que os descritos, sendo (100-)175-633(-1930)×15-85 $\mu \mathrm{m}$; entretanto, oogônios esféricos (28-52 $\mu \mathrm{m}$ diâm.) e piriformes (42-56×30-37 $\mu \mathrm{m})$ e oósporos (18-29 $\mu \mathrm{m}$ diâm.), menores que os estudados. A espécie foi isolada pela primeira vez no Brasil por Karling (1944), como hospedeira de Rozella achlyae Shanor, em amostras de água de Manaus (AM).

Achlya klebsiana Pieters, Bot. Gaz., 60: 486. 1915. Fig. 26-27

Talo monóico. Colônia em semente de sorgo com 3,0 cm diâm. após duas semanas. Gemas ausentes. Zoosporângios fusiformes, 330-650×30-50 $\mu \mathrm{m}$; renovação cimosa. Liberação dos zoósporos aclióide, zoósporos encistados, 10-12,5 ㅆm diâm. Oogônios laterais, esféricos, 27,5-65 $\mu \mathrm{m}$ diâm., ou piriformes, 37,5-45×50-62,5 $\mu \mathrm{m}$; parede oogonial lisa; pedúnculo reto, alguns pendentes, simples. Anterídios monóclinos e díclinos, quando monóclinos saindo de um ponto distante do oogônio; ramos e células anteridiais simples, atracação lateral, 1-3 por oogônio. Oósporos excêntricos, esféricos, 17,5-30 ㅆm diâm.; (1-)2-4(-8) por oogônio.

Material examinado: BRASIL. São Paulo: Santo André, Reserva Biológica de Paranapiacaba, amostras 

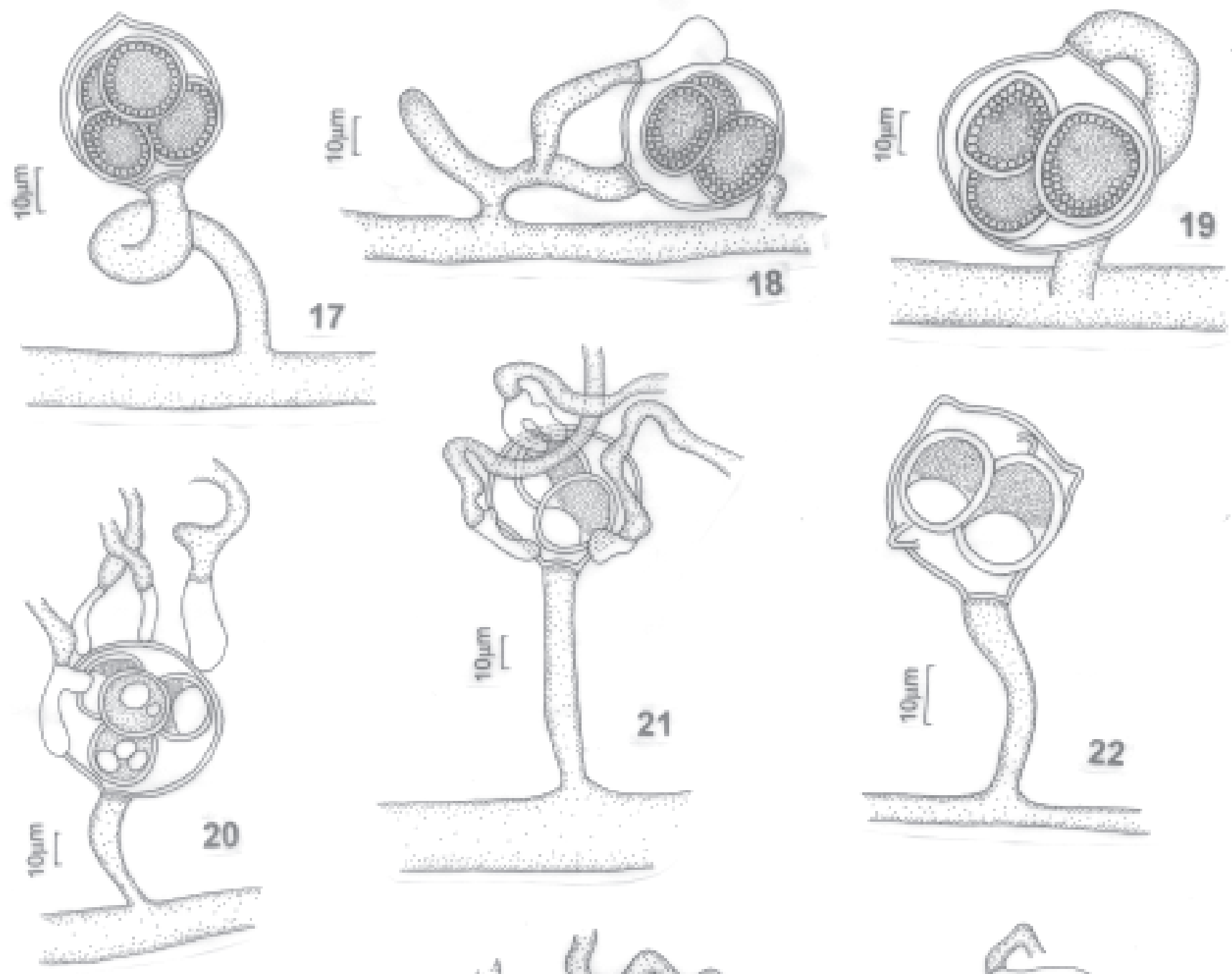

\section{7}
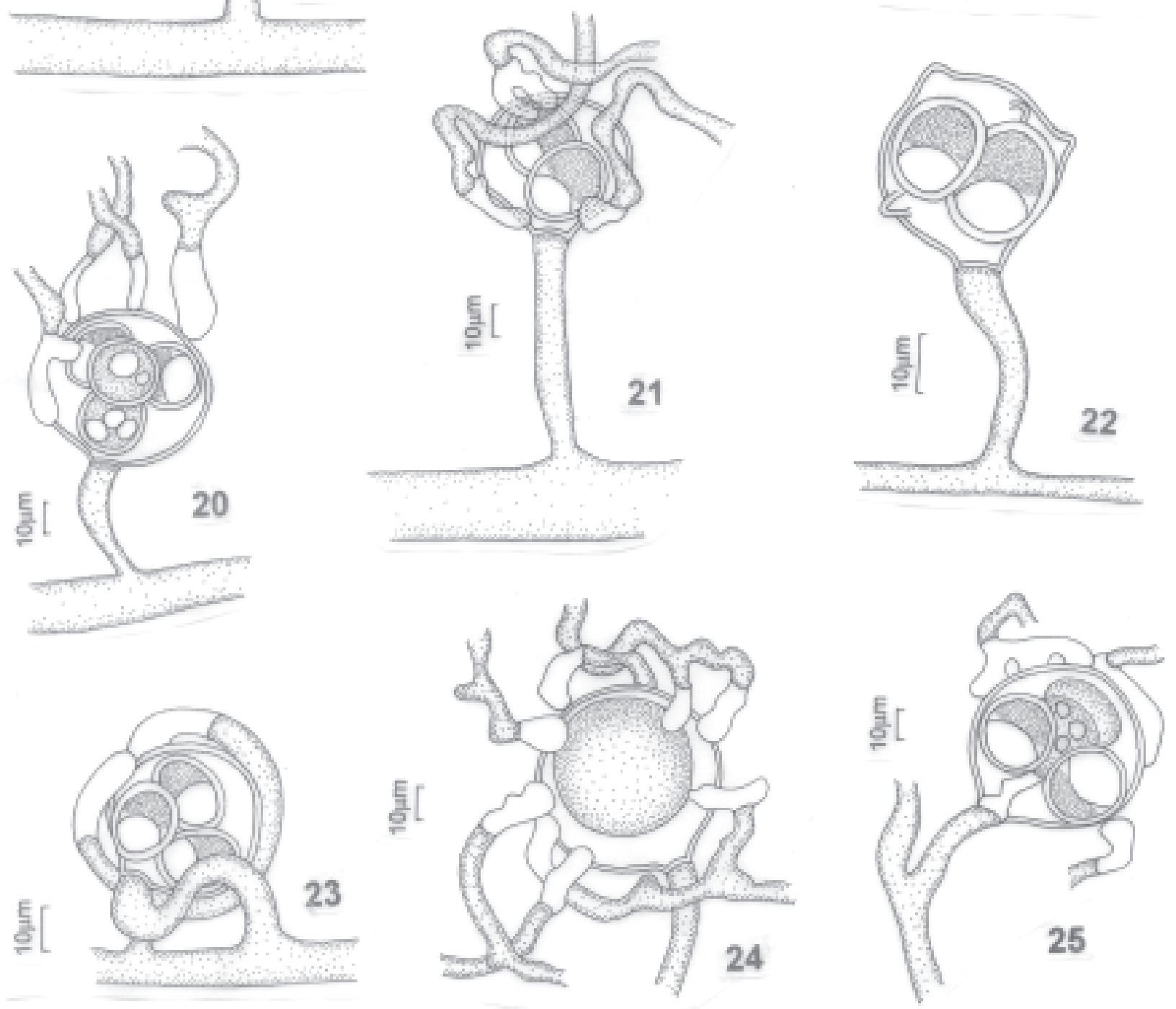

Figuras 17-25. 17-19. Achlya apiculata de Bary. 17. Oogônio, pedúnculo retorcido e oósporos. 18. Oogônio com oósporos subcêntricos e anterídio andrógino. 19. Oogônio com oósporos subcêntricos e pedúnculo pendente. 20-21. A. bisexualis Coker \& A. Couch. 20. Oogônio com oosferas abortivas e anterídios díclinos. 21. Oogônio com oósporos excêntricos e anterídios díclinos. 22-23. A. cambrica (Trow) Johnson. 22. Oogônio com substância proeminente aos poros. 23. Oogônio com oósporos excêntricos e anterídio monóclino. 24-25. A. flagellata Coker. 24. Oogônio com oosfera e anterídios díclinos. 25. Oogônio com anterídios díclinos, oósporos excêntricos e oosferas não maturando. 


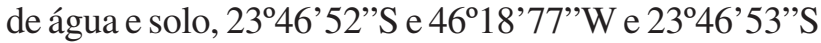
e 46¹8'69”'W, 26/II/2004, A.L. Gomes (SPC 1980, 1982).

As características dos espécimes estão de acordo com a descrição de Johnson (1956). Os oogônios e oósporos dos espécimes estudados por Pires-Zottarelli et al. (1996) apresentaram-se menores que os descritos, com oogônios de 31-45 بm diâm. e oósporos de 15-25 $\mu \mathrm{m}$ diâm. A espécie foi isolada pela primeira vez no Brasil por Beneke \& Rogers (1962), de amostras de água do Parque Estadual das Fontes do Ipiranga, São Paulo. Esta é a primeira citação para a Reserva.

Achlya orion Coker \& Couch, The Saprolegniaceae with notes on other water moulds: 112. 1923.

Fig. 28

Colônia medindo 2,0 cm diâm. em semente de sorgo após duas semanas. Gemas ausentes. Zoosporângios filiformes, fusiformes, 135-450× 15-40 $\mu \mathrm{m}$; renovação basipetalar e simpodial. Liberação dos zoósporos aclióide; zoosporos encistados, 10-15 $\mu \mathrm{m}$ diâm. Oogônios laterais, esféricos, 35-47,5 $\mu$ m diâm.; parede oogonial lisa; pedúnculos pendentes e retorcidos, alguns retos. Anterídios andróginos e monóclinos, alguns díclinos; poro no ponto de atracação da célula anteridial. Oosferas maturando. Oósporos excêntricos, esféricos, 20-27,5 $\mu \mathrm{m}$ diâm., ou ovais, 20-22,5×15-17,5 um, preenchendo todo o oogônio; 1-4 por oogônio.

Material examinado: BRASIL. São Paulo: Santo André, Reserva Biológica de Paranapiacaba, amostra de água, 2346'53"'S e 46¹8'69'W, 26/V/2004, A.L. Gomes (SPC 2001).

As estruturas sexuadas dos espécimes estudados por Pires-Zottarelli et al. (1996) apresentaram-se maiores, sendo descritos oogônios de 27-60 ㅆm diâm. e oósporos de 11-39 $\mu \mathrm{m}$ diâm. A espécie foi isolada pela primeira vez no Brasil por Beneke \& Rogers (1962), de amostras de água do Parque Estadual das Fontes do Ipiranga, São Paulo.

Achlya prolifera Nees, Nova Acta Acad. Leop. Carol., 11: 514. 1823.

Fig. 29

Colônia medindo 3,0-3,5 cm diâm. em semente de sorgo após duas semanas. Gemas ausentes. Zoosporângios fusiformes, $210-462,5 \times 27,5-40 \mu \mathrm{m}$; renovação basipetalar. Liberação dos zoósporos aclióide; zoósporos encistados, 10-12,5 ㅆm diâm. Oogônios laterais, esféricos, 37,5-52,5 $\mu \mathrm{m}$ diâm., ou piriformes,
42,5-67,5×50-60 $\mu \mathrm{m}$; parede oogonial lisa; pedúnculo simples. Anterídios díclinos envolvendo pedúnculo e oogônio, atracação lateral e por projeções, ramos divididos e células anteridiais simples. Oosferas maturando. Oósporos excêntricos, esféricos, 20-25 um diâm., preenchendo o oogônio; (2-)4-6(-10) por oogônio.

Material examinado: BRASIL. São Paulo: Santo André, Reserva Biológica de Paranapiacaba, amostras

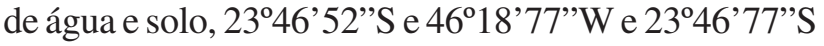
e 46 ${ }^{\circ} 18^{\prime} 56^{\prime \prime} \mathrm{W}, 26 / \mathrm{II} / 2004,26 / \mathrm{V} / 2004,18 / \mathrm{XI} / 2004$, A.L. Gomes (SPC 1984).

As características do espécime estão de acordo com a descrição de Johnson (1956) e Johnson et al. (2002). Pires-Zottarelli et al. (1996) descrevem oogônios maiores, de 43-65 $\mu \mathrm{m}$ diâm. e oósporos menores, de 17-23 $\mu \mathrm{m}$ diâm. A espécie foi isolada pela primeira vez no Brasil por Beneke e Rogers (1962), de amostras de água de Viçosa, Minas Gerais. Esta é a primeira citação para a Reserva.

Achlya radiosa Maurizio, Mitt. Deutsch. FischereiVereins 7: 57, figs. 18-19. 1899.

Fig. 30

Talo monóico. Colônia medindo 1,0 cm diâm. em semente de sorgo após duas semanas. Gemas ausentes. Zoosporângios fusiformes, 237,5-500× 20-30 $\mu \mathrm{m}$; renovação basipetalar. Liberação dos zoósporos aclióide; zoósporos encistados, 5-10 $\mu \mathrm{m}$ diâm. Oogônios laterais, esféricos, 40-47,5 ㅆm diâm.; parede com ornamentações mamiformes, algumas duplo-mamiformes 7,5-10 $\mu \mathrm{m}$ compr.; pedúnculo simples. Anterídio andrógino, atracação lateral, ramos e células anteridiais simples; 1-2 por oogônio. Oosferas maturando. Oósporos subcêntricos, esféricos, 15-27,5 بm diâm.; 1 por oogônio.

Material examinado: BRASIL. São Paulo: Santo André, Reserva Biológica de Paranapiacaba, amostras

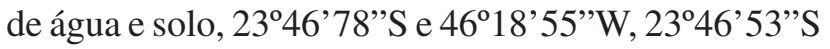

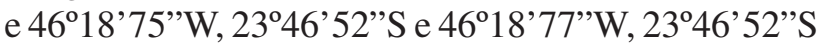

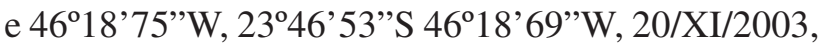
26/II/2004, 26/V/2004, 26/VIII/2004, A.L. Gomes (SPC 1966).

Os espécimes apresentaram estruturas sexuadas menores que as descritas por Johnson (1956) que cita oogônios esféricos de (35-)50-60(-75) um diâm., oósporos de (16-)28-38(-45) $\mu \mathrm{m}$ diâm. e por Johnson et al. (2002), que descrevem oogônios de 23-77 $\mu \mathrm{m}$ diâm. e oósporos de 19-41 um diâm. Os espécimes estudados por Pires-Zottarelli et al. (1996) apresentaram oogônios e oósporos maiores que os 

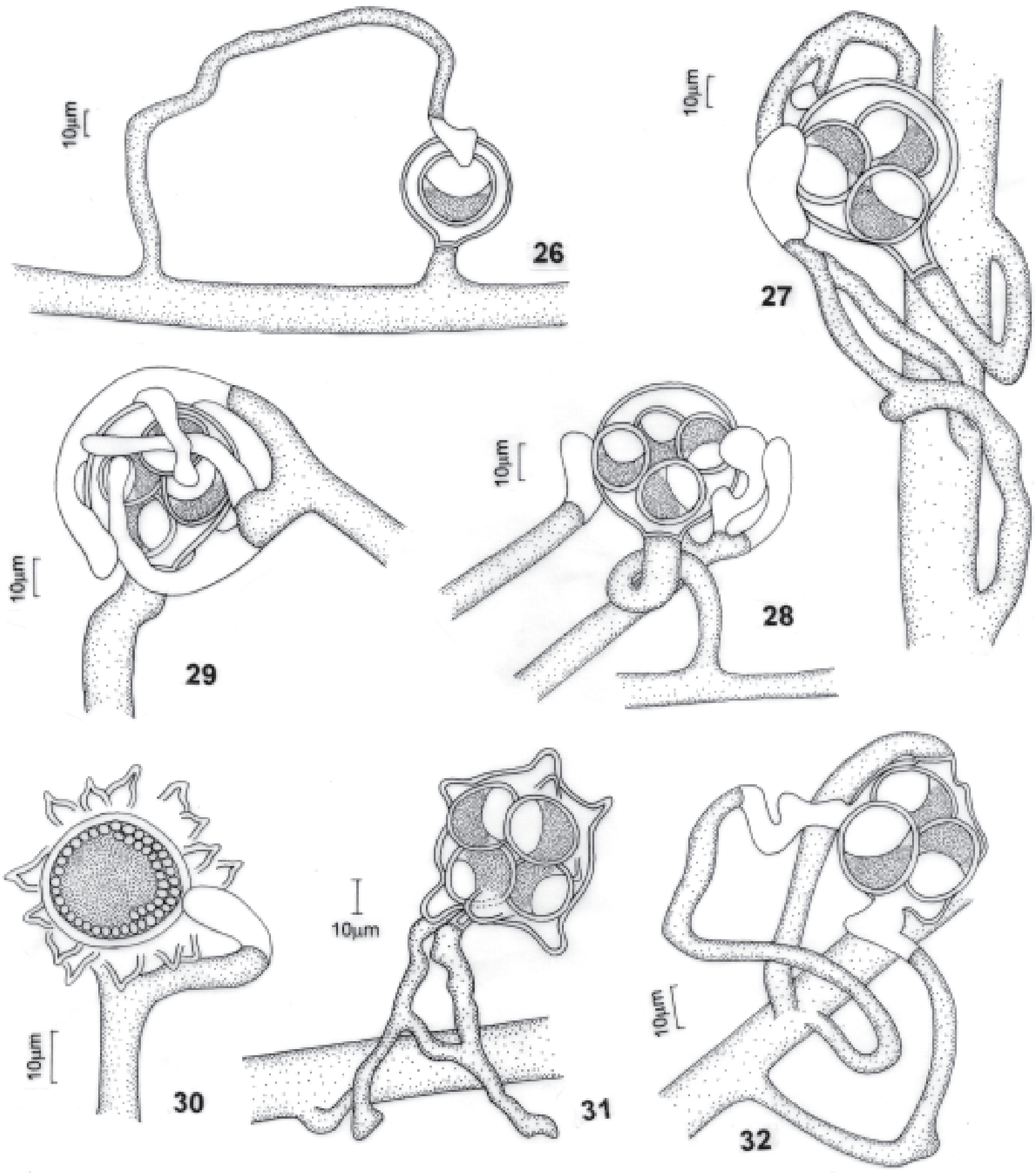

Figuras 26-32. 26-27. Achlya klebsiana Pieters. Oogônios com anterídios monóclinos. 28. A. orion Coker \& Couch. Oogônio com pedúnculo retorcido e anterídios diclinos. 29. A. prolifera C.G. Nees. Anterídios díclinos enrolando no oogônio. 30. A. radiosa Maurizio. Oogônio com ornamentações mamiformes, oósporo subcêntrico e anterídio andrógino. 31-32. A. subterranea Coker \& Braxton. 31 . Oogônio ornamentado e oósporos excêntricos. 32. Oogônio com anterídios monóclinos, pedúnculo pendente e oósporos excêntricos. 
descritos, 22-57 $\mu \mathrm{m}$ diâm. e 16-32 $\mu \mathrm{m}$ diâm., respectivamente. As estruturas sexuadas do espécime estudado por Milanez (1969) apresentaram-se maiores, tendo sido descritos oogônios de 35-70 $\mu \mathrm{m}$ diâm. e oósporos de 25-41 $\mu \mathrm{m}$ diâm. A espécie foi isolada pela primeira vez no Brasil por Milanez (1969), de amostras de solo do Rio Santa Luzia, Mato Grosso do Sul.

Achlya subterranea Coker \& Braxton, J. Elisha Mitchell Sci. Soc. 42: 141. 1926.

Fig. 31-32

Talo monóico. Colônia medindo $2,5 \mathrm{~cm}$ diâm. em semente de sorgo após duas semanas. Gemas ausentes. Zoosporângios fusiformes, 175-762,5× 25-40 $\mu \mathrm{m}$; renovação basipetalar. Liberação dos zoósporos aclióide; zoósporos encistados, 10-12,5 $\mu \mathrm{m}$ diam. Oogônios laterais, esféricos, 22,5-55 $\mu$ m diâm.; parede oogonial com ornamentações truncadas; pedúnculo pendente. Anterídios monóclinos, díclinos e andróginos, ramos e células anteridiais simples, atracação lateral. Oosferas maturando. Oósporos excêntricos, esféricos, 20-30 $\mu \mathrm{m}$ diâm.; 2-4 por oogônio.

Material examinado: BRASIL. São Paulo: Santo André, Reserva Biológica de Paranapiacaba, amostras

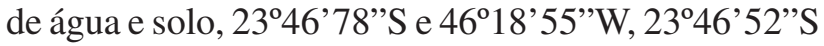

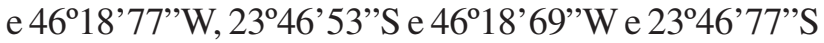
e 46¹8'56”'W, 26/II/2004, 26/V/2004, 26/VIII/2004, 18/XI/2004, A.L. Gomes (SPC 1993, 1994, 1999).

Os espécimes estudados por Johnson (1956) apresentaram estruturas maiores que as observadas, com zoosporângios acima de $625 \mu \mathrm{m}$ compr., oogônios

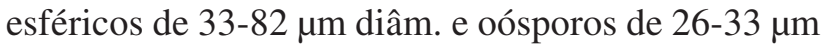
diâm. As estruturas sexuadas dos espécimes descritos por Johnson et al. (2002) eram maiores, sendo oogônios de (30)58-78(86) um diâm. e oósporos de (13)22-28(37) $\mu \mathrm{m}$ diâm. A espécie foi isolada pela primeira vez no Brasil por Milanez et al. (1994), de amostras de solo de áreas da Mata Atlântica. Esta é a primeira citação para a Reserva.

Aphanomyces cladogamus Drechsler, J. Agric. Res., 38: 335. 1929.

Fig. 33

Micélio presente em ecdise de cobra. Gemas ausentes. Zoosporângios longos, filiformes. Zoósporos não observados. Oogônios laterais, esféricos, 15-22,5 $\mu \mathrm{m}$ diâm.; parede externa lisa e interna abaulada; pedúnculo simples. Anterídios não observados. Oósporos com gotícula lipídica excêntrica, esféricos, 10,5-16,5 $\mu$ m diâm.; 1 por oogônio.
Material examinado: BRASIL. São Paulo: Santo André, Reserva Biológica de Paranapiacaba, amostras

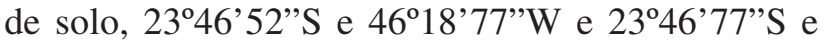
$46^{\circ} 18^{\prime} 56^{\prime \prime} \mathrm{W}, 26 / \mathrm{II} / 2004,26 / \mathrm{V} / 2004$, A.L. Gomes.

Os espécimes apresentaram estruturas sexuadas menores que as descritas por Scott (1961), que cita oogônios de 19-33 um diâm. e oósporos de 15-25 $\mu \mathrm{m}$ diâm., e por Johnson et al. (2002), os quais citam

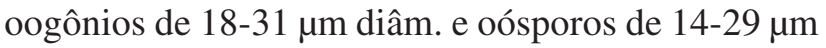
diâm. Entretanto, as características apresentadas pelos espécimes concordam com as citadas por Gomes et al. (2003). Devido à contaminação não foram preservados. Esta espécie foi isolada pela primeira vez no Brasil de amostras de água e solo de áreas de cerrado do Estado de São Paulo (Gomes et al. 2003). Esta é a primeira citação para a Reserva.

Aphanomyces irregulare Scott, Va. Agr. Exp. Sta. Tech. Bull. A monograph of the genus Aphanomyces 151: 47-48. 1961.

Fig. 34-35

Colônia medindo 1,0 cm diâm. em semente de sorgo após duas semanas. Gemas ausentes. Zoosporângios longos, filiformes. Zoósporos encistados, 7,5-10 $\mu \mathrm{m}$ diâm. Oogônios esféricos, 27,5-37,5 $\mu \mathrm{m}$ diâm., com parede interna e externa irregular; pedúnculo simples. Anterídios díclinos, células e ramos anteridiais simples, atracação apical; 1-2 por oogônio. Oósporos subcêntricos, esféricos, 20-27,5 $\mu$ m diâm.; 1 por oogônio.

Material examinado: BRASIL. São Paulo: Santo André, Reserva Biológica de Paranapiacaba, amostra de água, 2346'78”S e 46¹8'55”'W, 20/XI/2003, A.L. Gomes (SPC 1998).

O espécime apresentou estruturas sexuadas maiores que as citadas por Scott (1961), que descreve oogônios de 15-28 $\mu$ m diâm. e oósporos de 12-20 $\mu \mathrm{m}$ diâm.; Pires-Zottarelli \& Milanez (1993), os quais citam oogônios de 18-22 $\mu$ m diâm. e oósporos de 16-21 $\mu \mathrm{m}$ diâm. e Rocha \& Pires-Zottarelli (2002), que citam oósporos de 15-20 $\mu$ m diâm. Os espécimes estudados por Gomes et al. (2003) apresentaram estruturas sexuadas menores, tendo sido descritos oogônios de 17-25 $\mu \mathrm{m}$ diâm. e oósporos de 12-20 $\mu \mathrm{m}$ diâm. A espécie foi isolada pela primeira vez no Brasil por PiresZottarelli \& Milanez (1993) de água e solo da Represa do Lobo, Brotas-Itirapina (SP). Esta é a primeira citação para a Reserva.

Aphanomyces stellatus de Bary, Jahrb. Wiss. Bot., 2: 178, pl. 19, figs. 1-13. 1860.

Fig. 36-38 
Colônia com 1,4 cm diâm. em semente de sorgo após duas semanas. Gemas ausentes. Zoosporângios longos, filiformes. Liberação dos zoósporos aclióide; zoósporos encistados 8-10 $\mu \mathrm{m}$. Oogônios laterais, esféricos, 25-37,5 $\mu \mathrm{m}$ diâm., com ornamentações tuberculadas, 5-12,5 $\mu \mathrm{m}$ compr.; pedúnculo simples. Anterídios díclinos e monóclinos, 1-2 por oogônio. Oosferas maturando. Oósporos com gotícula lipídica subcêntrica, esféricos, 15-22,5 um diâm.; 1 por oogônio.

Material examinado: BRASIL. São Paulo: Santo André, Reserva Biológica de Paranapiacaba, amostras

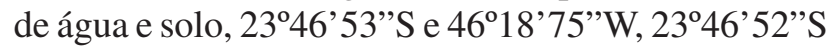
e 46 $18^{\prime} 77^{\prime \prime} W, 23^{\circ} 46^{\prime} 52^{\prime \prime}$ 'S e $46^{\circ} 18^{\prime} 75^{\prime \prime}$ 'W e $23^{\circ} 46^{\prime} 77^{\prime \prime}$ 'S e 46 ${ }^{\circ} 18^{\prime} 56^{\prime \prime}$ ', 20/XI/2003, 26/V/2004, 26/VIII/2004, A.L. Gomes (SPC 1987).

As características dos espécimes estudados concordam com Scott (1961) e Johnson et al. (2002). Os zoósporos, oogônios e as ornamentações do espécime estudado por Pires-Zottarelli et al. (1996) apresentaram-se menores, 5,5-9 $\mu \mathrm{m}, 17,5-23,5 \mu \mathrm{m}$ diâm. e 4-6,5 $\mu \mathrm{m}$ compr., respectivamente, do que os aqui descritos. A espécie foi isolada pela primeira vez no Brasil por Beneke e Rogers (1962), de amostras de água do Parque Estadual das Fontes do Ipiranga, São Paulo. É a primeira citação para a Reserva.

Brevilegnia diclina Harvey, J. Elisha Mitchell Sci. Soc.: 243. 1927.

Fig. 39-42

Colônia medindo $1,4 \mathrm{~cm}$ diâm. em semente de sorgo após duas semanas. Gemas ausentes. Zoosporângios clavados, 67,5-250×17,5-25 $\mu \mathrm{m}$; renovação basipetalar e/ou simpodial. Zoósporos dispostos em duas fileiras no zoosporângio; liberação dos zoósporos brevilegnióide, zoósporos encistados,

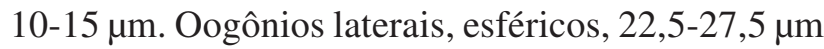
diâm., alguns irregulares; parede oogonial lisa com algumas irregularidades; pedúnculo simples, longo, 25-100 $\mu \mathrm{m}$ compr. Anterídios díclinos, ramos anteridiais divididos e células anteridiais simples, atracação lateral e apical; 1-3 por oogônio. Oosferas maturando. Oósporos excêntricos, esféricos, 17,5-22,5 $\mu \mathrm{m}$ diâm.; 1 por oogônio, não preenchendo o oogônio.

Material examinado: BRASIL. São Paulo: Santo André, Reserva Biológica de Paranapiacaba, amostras

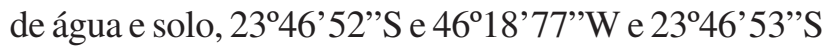
e 46¹8'69”'W, 26/II/2004, A.L. Gomes (SP 381550).

Os espécimes apresentaram zoosporângios pouco menores que os descritos por Johnson et al. (2002), que citam de 60-327×9-41 $\mu \mathrm{m}$. Esta espécie foi isolada pela primeira vez no Brasil por Rogers et al. (1970), de amostras de solo do Parque Estadual das Fontes do Ipiranga, São Paulo. Esta é a primeira citação para a Reserva.

Brevilegnia linearis Coker \& Braxton, in Coker, J. Elisha Mitchell Sci. Soc. 42: 214-215. 1927.

Fig. 43-45

Colônia medindo $1,5 \mathrm{~cm}$ diâm. em semente de sorgo após duas semanas. Gemas ausentes. Zoosporângios longos, filiformes, 52,5-550×7,5-12,5 $\mu \mathrm{m}$; renovação simpodial. Zoósporos dispostos em única fileira no zoosporângio; liberação dos zoósporos brevilegnióide; zoósporos encistados, 7,5-10 $\mu$ m diâm., ou alongados, 12,5-30×7,5-10 $\mu \mathrm{m}$. Oogônios laterais, esféricos, 20-27,5 m diâm.; parede oogonial com papilas, 2,5-10 $\mu$ m compr.; pedúnculo longo, helicoidal. Anterídios andróginos, ramos e células anteridiais simples; 1 por oogônio. Oosferas maturando. Oósporos excêntricos, esféricos, 12,5-17,5 $\mu$ m diâm., 1 por oogônio.

Material examinado: BRASIL. São Paulo: Santo André, Reserva Biológica de Paranapiacaba, amostra

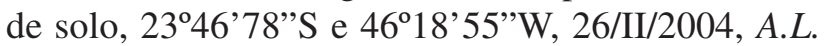
Gomes (SPC 1983).

As características do espécime estão de acordo com Johnson et al. (2002), mas os oogônios foram maiores que os descritos por Pires-Zottarelli \& Milanez (1993), os quais citam de 15-22 $\mu$ m diâm. Esta espécie foi isolada no Brasil por Pires-Zottarelli \& Milanez (1993), de amostras de água e solo da Represa do Lobo, Brotas-Itirapina (SP). Esta é a primeira citação para a Reserva.

Dictyuchus pseudodictyon Coker \& Braxton ex Couch, J. Elisha Mitchell Sci. Soc. 46: 228-229. 1931.

Fig. 46-48

Colônia medindo $1,5 \mathrm{~cm}$ diâm. em semente de sorgo após duas semanas. Gemas ausentes. Zoosporângios clavados, 112,5-500×22,5-32,5 $\mu \mathrm{m}$; rede verdadeira. Liberação dos zoósporos dictióide, zoósporos encistados, 12,5 m diâm. Oogônios laterais, esféricos, 22,5-37,5 $\mu \mathrm{m}$ diâm.; parede oogonial lisa; pedúnculo simples. Anterídios diclinos, envolvendo o oogônio, algumas vezes ausentes; células e ramos anteridiais simples, 1-10 por oogônio. Oosferas maturando. Oósporos excêntricos, esféricos, 20-35 $\mu \mathrm{m}$ diâm.; 1 por oogônio.

Material examinado: BRASIL. São Paulo: Santo André, Reserva Biológica de Paranapiacaba, amostras

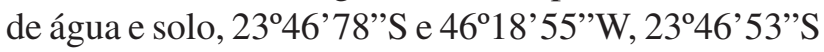

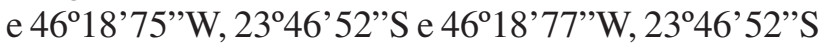



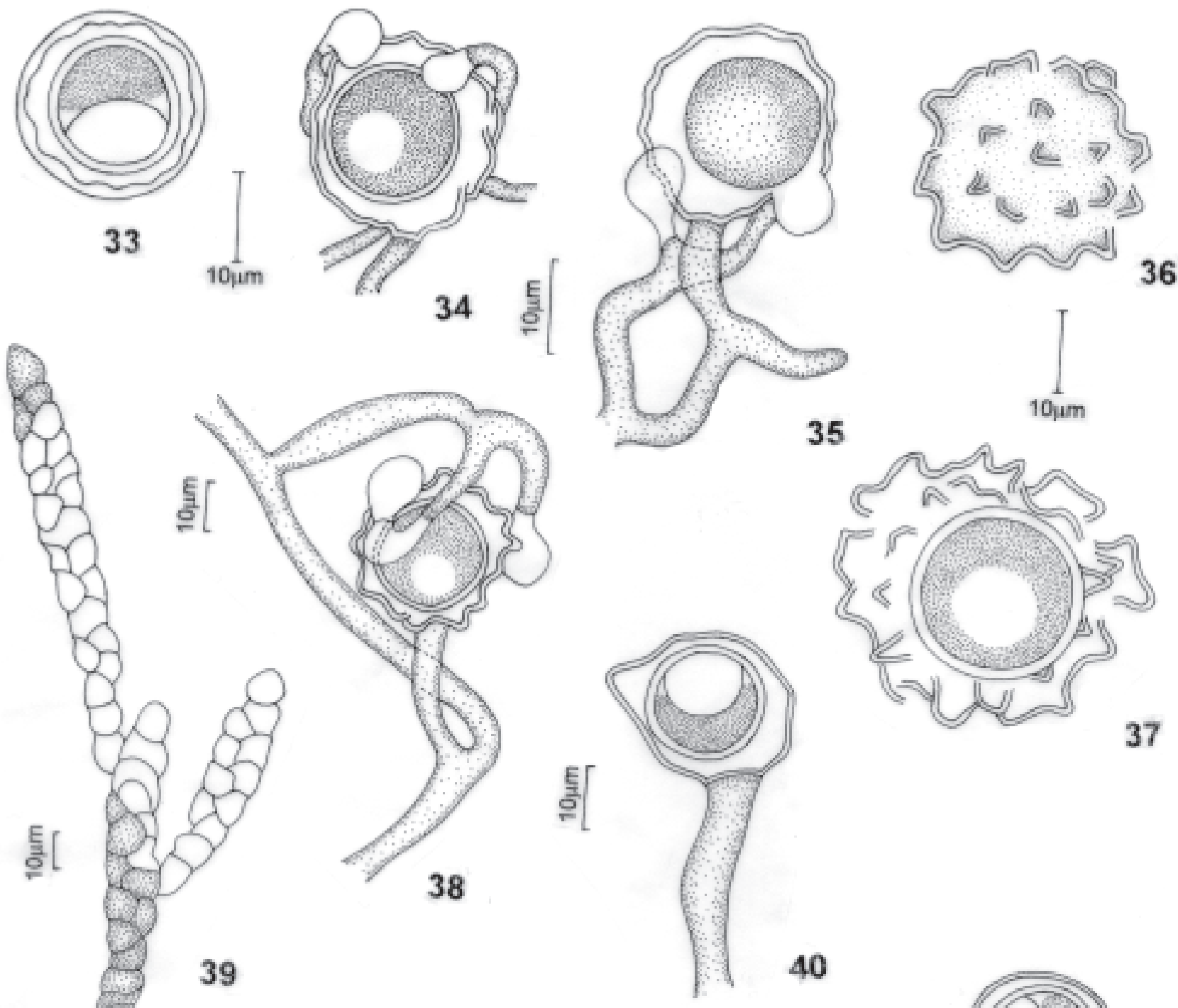

35
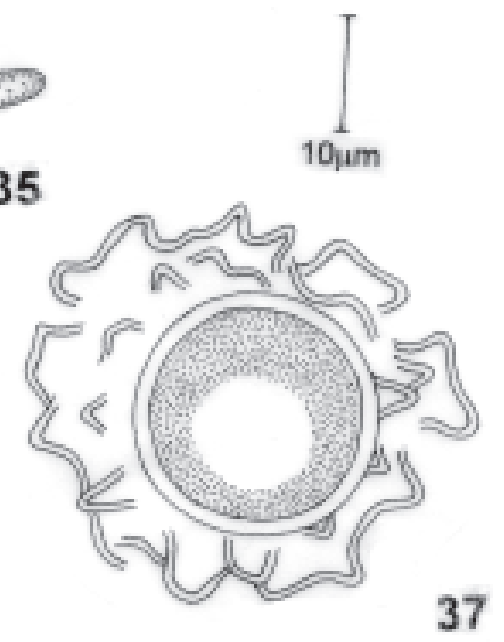

40
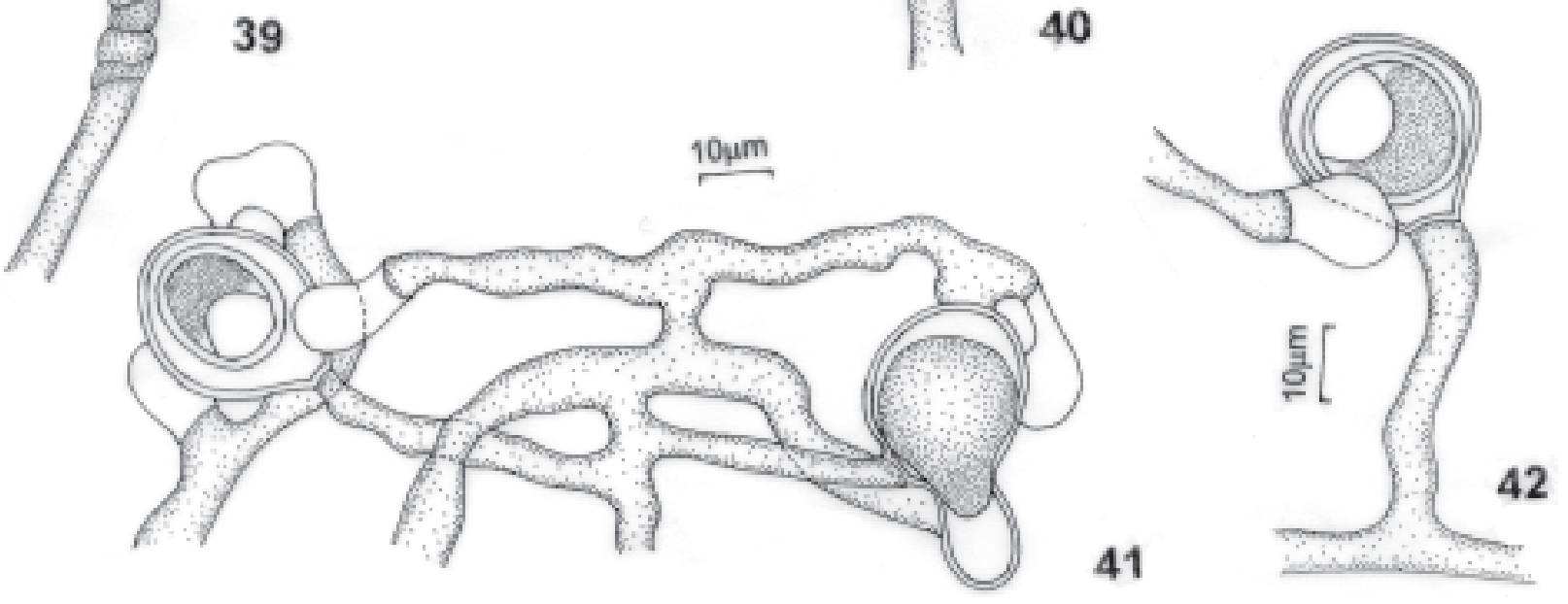

Figuras 33-42. 33. Aphanomyces cladogamus Dreschler. Oogônio e oósporo excêntrico. 34-35. A. irregulare Scott. 34. Oogônio com parede irregular, oósporo subcêntrico e anterídios díclinos. 35. Oogônio com parede irregular, oosfera e anterídio andrógino. 36-38. A. stellatus de Bary. 36. Oogônio ornamentado. 37. Oogônio com oósporo subcêntrico. 38. Oogônio com anterídios monóclinos. $39-42$. Brevilegnia diclina Harvey. 39. Zoosporângio com duas fileiras de zoósporos. 40. Oogônio com oósporo excêntrico. 41. Oogônios com anterídios díclinos e oósporo excêntrico. 42. Oogônios com oósporo excêntrico e anterídio diclino. 

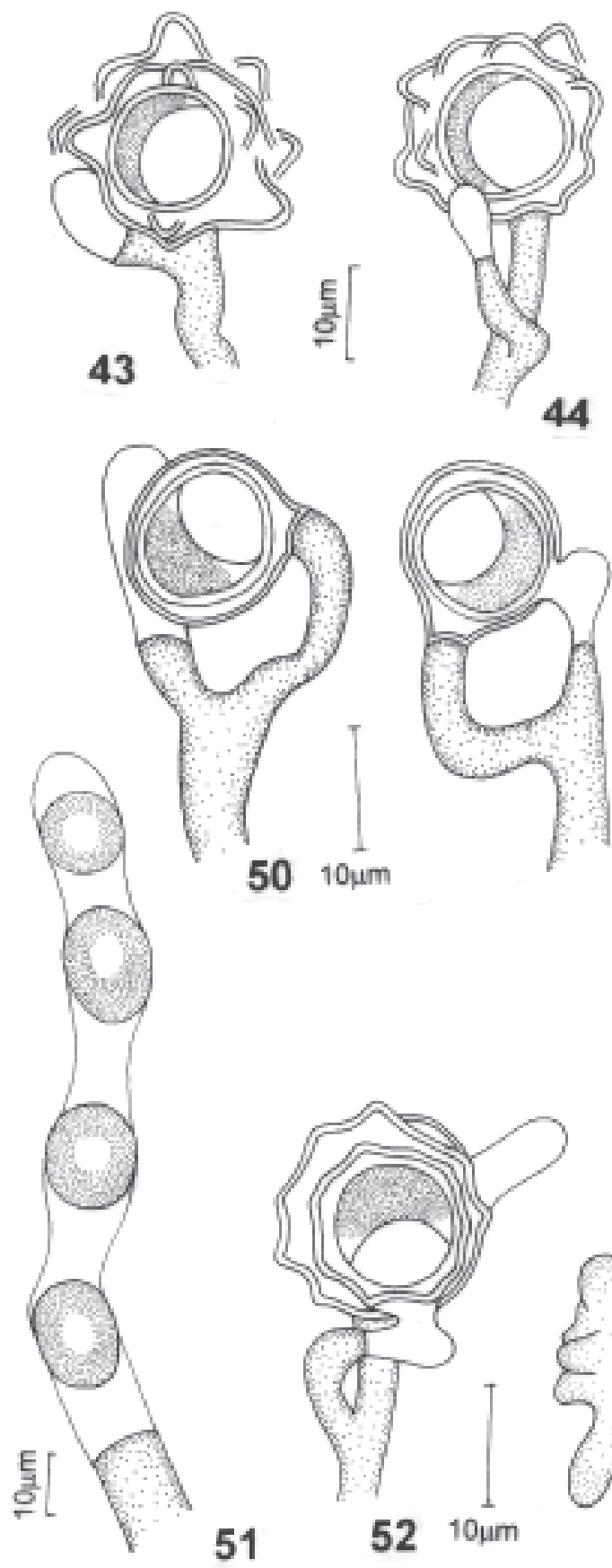

51

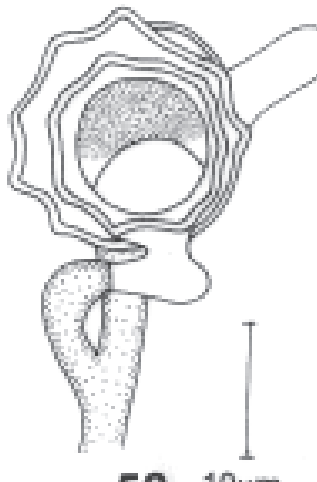

$5210 \mu m$

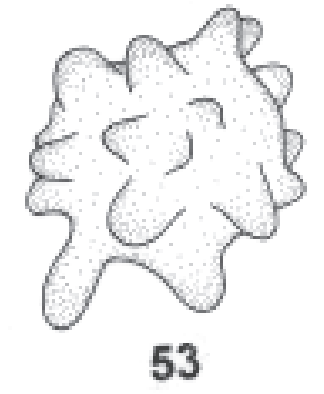

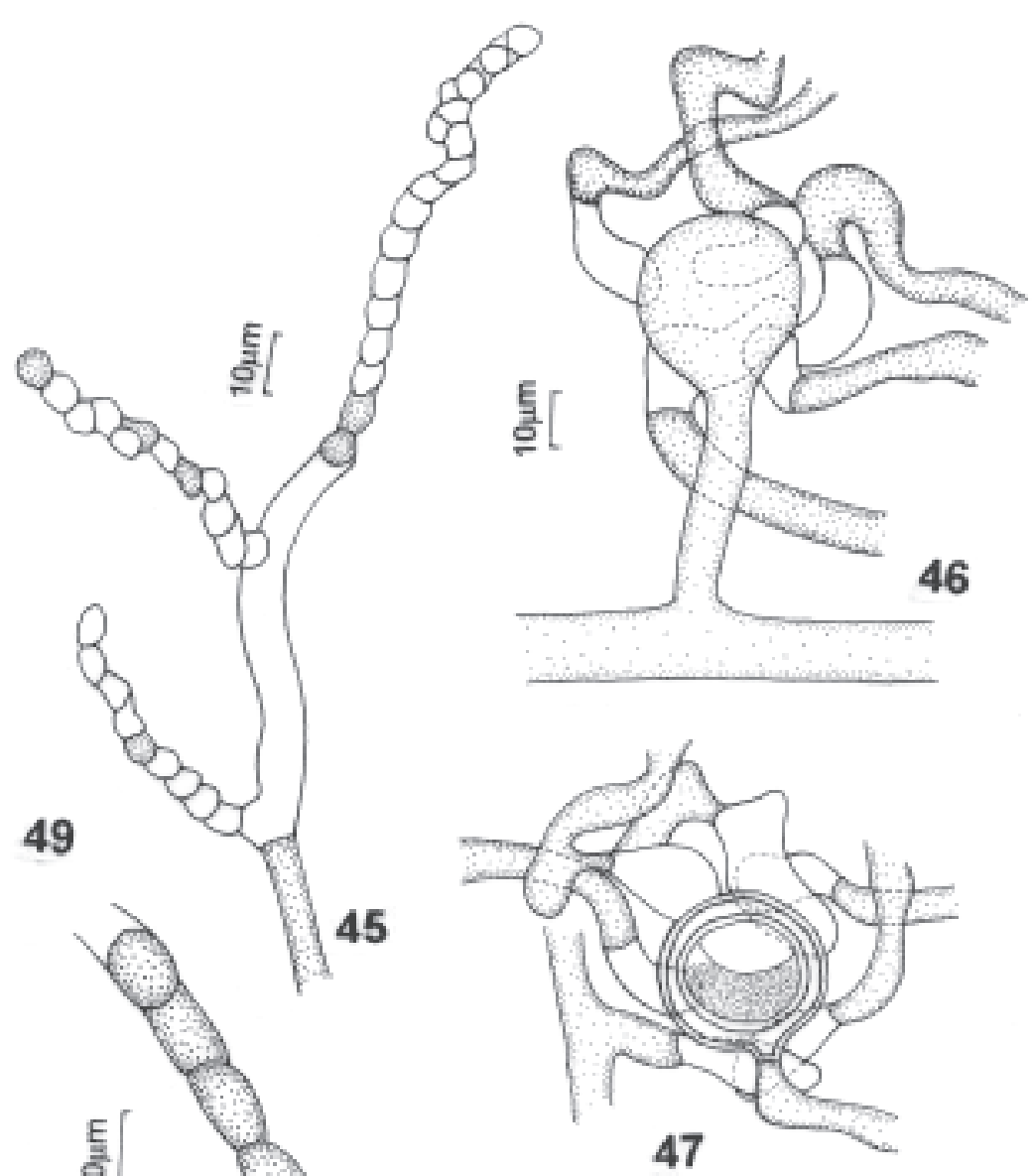

47

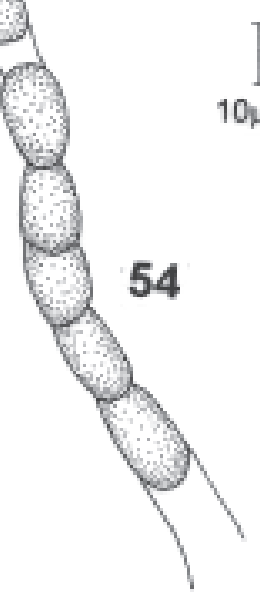

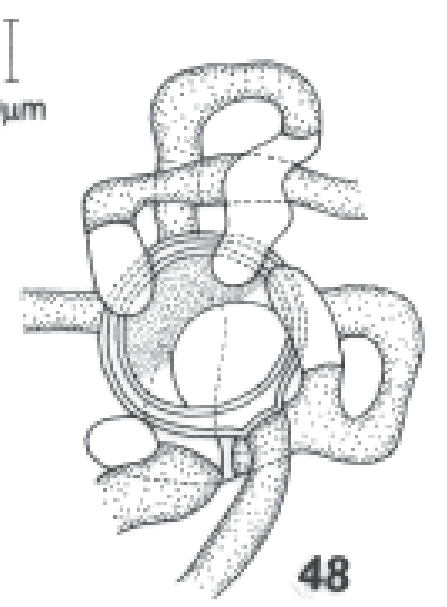

Figuras 43-54. 43-45. Brevilegnia linearis Coker \& Braxton. 43-44. Oogônios com oósporos excêntricos e anterídios andróginos. 45. Zoosporângio. 46-48. Dictyuchus pseudodictyon Coker \& Braxton. 46. Oogônio jovem com anterídios. 47-48. Oogônios com oósporos excêntricos e anterídios díclinos. 49-51. Geolegnia inflata Coker \& Harvey. 49-50. Oogônios com oósporos excêntricos e anterídios andróginos. 51. Aplanosporângio com aplanósporos. 52-54. Leptolegnia eccentrica Coker \& Matthews. 52. Oogônio, oósporo com parede enrugada e anterídio andrógino. 53. Oogônio papilado. 54. Zoosporângio. 


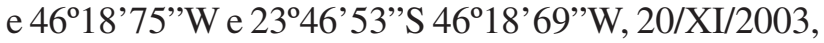
26/V/2004, 26/VIII/2004, 18/XI/2004, A.L. Gomes (SPC 1995).

Rocha \& Pires-Zottarelli (2002) descreveram estruturas menores, com zoosporângios de 115-250x 10-12 $\mu \mathrm{m}$ e oósporos de 22-27 $\mu \mathrm{m}$ diâm. As características dos espécimes estão de acordo com a descrição de Johnson et al. (2002). A espécie foi isolada pela primeira vez no Brasil por Beneke \& Rogers (1962), de amostras de água do Parque Estadual das Fontes do Ipiranga, São Paulo. Esta é a primeira citação para a Reserva.

Geolegnia inflata Coker \& Harvey, J. Elisha Mitchell Sci. Soc. 41: 153. 1925.

Fig. 49-51

Colônia com 1,5 cm diâm. em semente de sorgo após duas semanas. Aplanosporângios com 4-10 aplanósporos. Aplanósporos 8,25-15 $\mu$ m diâm.; ou ovais ou alongados, 9-19,5×7,5-12 $\mu \mathrm{m}$. Oogônios laterais, 13,5-15 um diâm.; parade oogonial lisa; pedúnculo simples. Anterídios andróginos, 1 por oogônio. Oosferas maturando. Oósporos excêntricos, 12-15 ㅆ diâm.; 1 por oogônio.

Material examinado: BRASIL. São Paulo: Santo André, Reserva Biológica de Paranapiacaba, amostra de solo, 2346' 52"'S e 46 $18^{\circ} 75^{\prime \prime} \mathrm{W}, 26 / \mathrm{VIII} / 2004$, A.L. Gomes (SP 381555).

Milanez (1970) descreveu aplanósporos esféricos de 11-20 $\mu$ m diâm. e alongados de 14,5-42×6,5-15,5 $\mu \mathrm{m}$, maiores que os descritos. $\mathrm{O}$ espécime estudado por Pires-Zottarelli et al. (1996) apresentou aplanósporos esféricos (12-23 $\mu \mathrm{m}$ diâm.) e oogônios esféricos (13-23,4 $\mu \mathrm{m}$ diâm.), maiores que os aqui descritos. Os oogônios do espécime estudado eram menores que os descritos por Gomes et al. (2003), que citam oogônios de 15-19 $\mu \mathrm{m}$ diâm. A espécie foi isolada pela primeira no Brasil por Milanez (1970), de amostras de solo perto do Córrego Jataí, Marabá Paulista (SP). Esta é a primeira citação para a Reserva.

Leptolegnia eccentrica Coker \& Matthews, in Coker, J. Elisha Mitchell Sci. Soc. 42: 215. 1927.

Fig. 52-54

Colônia medindo 1,5-2,0 cm diâm. em semente de sorgo após duas semanas; também presente em ecdise de cobra. Zoosporângios filiformes, longos. Zoósporos encistados 6-8 $\mu$ m diâm. Gemas ausentes. Oogônios laterais, esféricos, 15-27 um diâm., alguns catenulados; parede oogonial lisa com algumas papilas, 1-8 $\mu \mathrm{m}$ compr.; pedúnculo simples. Anterídios andróginos, 1 por oogônio. Oosferas maturando. Oósporos excêntricos, esféricos, 12-22 $\mu \mathrm{m}$ diâm.; parede irregular ou enrugada; 1 por oogônio.

Material examinado: BRASIL. São Paulo: Santo André, Reserva Biológica de Paranapiacaba, amostras de solo, 2346' $52^{\prime \prime}$ S e $46^{\circ} 18^{\prime} 77^{\prime}$ 'W e $23^{\circ} 46^{\prime} 52^{\prime \prime}$ S e 46 ${ }^{\circ} 18^{\prime} 75^{\prime}$ 'W, 20/XI/2003, 18/XI/2004, A.L. Gomes (SPC 2004).

As estruturas sexuadas dos isolados analisados por Johnson et al. (2002) eram maiores que as descritas, com oogônios de 16-43 um diâm. e oósporos de 14-38 $\mu$ m diâm. No Brasil, a espécie foi isolada de amostras de solo, de local não especificado, por R.L. Seymour (Johnson et al. 2002). Esta é a primeira citação para o Estado de São Paulo.

Pythiopsis humphreyana Coker, Mycologia 6: 292.1914. Fig. 55-58

Colônia medindo 1-1,5 cm diâm. em semente de sorgo após duas semanas. Gemas presentes. Zoosporângios esféricos, 32,5-47,5 ㅆm diâm., irregulares, 35-112,5×17,5-40 $\mu \mathrm{m}$. Zoósporos encistados, $10 \mu \mathrm{m}$ diâm. Oogônios laterais, piriformes, 25-55×27,5-40,5 $\mu \mathrm{m}$; parede oogonial lisa, alguns com papilas de 4,5-24 $\mu \mathrm{m}$ compr.; pedúnculo simples. Anterídios andróginos, monóclinos e díclinos; células anteridiais simples e ramificadas, tubo de fertilização presente. Oosferas maturando. Oósporos esféricos, 22,5-27 $\mu \mathrm{m}$ diâm.; cêntricos e subcêntricos, em sua maioria, 1-2 por oogônio.

Material examinado: BRASIL. São Paulo: Santo André, Reserva Biológica de Paranapiacaba, amostra de solo, 23\%46"S e 46 18”'W, 26/VIII/2004, A.L. Gomes (SPC 2002).

Johnson et al. (2002) citam zoosporângios esféricos de 60-308×17-81 $\mu \mathrm{m}$ e oósporos de 20-40 $\mu \mathrm{m}$ diâm., tendo sido a espécie isolada pela primeira vez no Brasil de amostras de solo da Amazônia. Esta é a primeira citação para o Estado de São Paulo.

Pythiopsis irregularis Seymour, Systematics of the Saprolegniaceae: New taxa 92: 3. 2005.

Fig. 59-61

Colônia com $1 \mathrm{~cm}$ diâm. em semente de sorgo após duas semanas. Gemas presentes. Zoosporângios filiformes, irregulares, 52,5-87,5×12,5-50 $\mu \mathrm{m}$. Liberação saprolegnióide; zoósporos encistados 
7,5-15 $\mu \mathrm{m}$. Oogônios ornamentados, esféricos, (30-)35-45(-60) $\mu \mathrm{m}$, naviculados, 32,5-57,5×30-50 $\mu \mathrm{m}$, alguns irregulares; ornamentações papiladas e truncadas de 5-10 $\mu \mathrm{m}$ compr.; pedúnculos simples. Anterídios andróginos, 1 por oogônio, células anteridiais divididas, atracação lateral. Oosferas maturando. Oósporos cêntricos, alguns subcêntricos, esféricos, 22,5-30 $\mu$ m diâm., 2-3 por oogônio.

Material examinado: BRASIL. São Paulo: Santo André, Reserva Biológica de Paranapiacaba, amostras

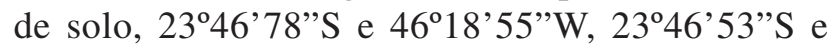

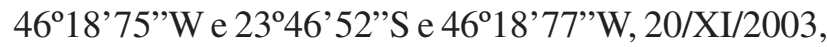
26/II/2004, 18/XI/2004, A.L. Gomes (SPC 1965).

O espécime estudado difere da descrição original de Johnson et al. (2005) por apresentar zoosporângios menores que os descritos pelos autores, 90-115x 77-86 $\mu \mathrm{m}$. No Brasil, a espécie foi isolada de amostras de solo, no Amazonas (Johnson et al. 2005).

Saprolegnia diclina Humphrey. Trans. Amer. Phil. Soc. (N.S.) 17: 109, pl. 17, figs. 50-53. 1893.

Fig. 62-64

Colônia de 1,5 cm diâm. em semente de sorgo após duas semanas. Gemas presentes. Zoosporângios filiformes com proliferação interna, 112,5-312,5× 15-50 $\mu \mathrm{m}$. Liberação dos zoósporos saprolegnióide, zoósporos encistados, 7,5-12,5 $\mu \mathrm{m}$ diâm. Oogônios laterais, esféricos, 37,5-82,5 $\mu$ m diâm., ou piriformes, 47,5-175×37,5-110 $\mu \mathrm{m}$; parede oogonial lisa com poros; pedúnculo simples. Anterídios díclinos, algumas vezes monóclinos; atracação lateral e apical, ramos simples e células anteridiais divididas; 1-4 por oogônio. Oosferas maturando. Oósporos subcêntricos, alguns cêntricos, esféricos, (17,5-)25-35(-42,5) $\mu \mathrm{m}$ diâm.; (1-)2-8(-12) por oogônio.

Material examinado: BRASIL. São Paulo: Santo André, Reserva Biológica de Paranapiacaba, amostras

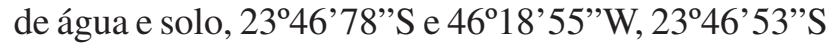
e 46 $18^{\circ} 75^{\prime \prime} W, 23^{\circ} 46^{\prime} 52^{\prime \prime}$ 'S e $46^{\circ} 18^{\prime} 77^{\prime \prime} W, 23^{\circ} 46^{\prime} 52^{\prime \prime} S$

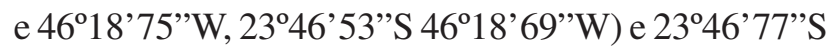
e 46² $18^{\prime} 56^{\prime \prime} \mathrm{W}, 20 / \mathrm{XI} / 2003,26 / \mathrm{V} / 2004,26 / \mathrm{VIII} / 2004$, A.L. Gomes (SPC 1961, 1962, 1967, 1988).

Os espécimes estudados apresentaram oogônios catenulados e sésseis, e poros além do ponto de atracação. Os oogônios do espécime estudado por Pires-Zottarelli et al. (1996) apresentaram-se maiores, com 32-110 $\mu$ m diâm., e oósporos menores, com 12-36 um diâm. Seymour (1970) cita oósporos de 12-36 $\mu \mathrm{m}$ diâm., menores que os aqui descritos. Johnson et al. (2002) descrevem oogônios piriformes de 54-146×18-72 $\mu \mathrm{m}$, menores do que os dos espécimes estudados. Beneke \& Rogers (1962) citam oogônios maiores, de 90-97 $\mu \mathrm{m}$. A espécie foi isolada pela primeira vez no Brasil por Beneke \& Rogers (1962), de amostras de água do Instituto de Botânica de São Paulo. Esta é a primeira citação para a Reserva.

Saprolegnia subterranea (Dissman) Seymour, Nova Hedwigia 19:59. 1970.

Isoachlya subterranea Dissmann 1931.

Fig. 65-66

Colônia medindo 2,0 cm diâm. em semente de sorgo após duas semanas. Zoosporângios fusiformes,

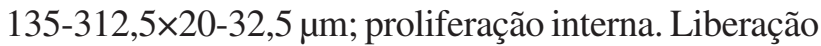
dos zoósporos saprolegnióide, 10-12 $\mu \mathrm{m}$. Oogônios laterais, intercalares, catenulados; esféricos, 25-32,5 $\mu \mathrm{m}$ diâm., ou piriformes, $25-35 \times 22,5-30 \mu \mathrm{m}$; parede oogonial lisa, poros no ponto de atracação; pedúnculo simples. Anterídios andróginos, ramos e células anteridiais simples, atracação lateral; 1 por oogônio. Oosferas maturando. Oósporos subexcêntricos, esféricos, 17,5-25 $\mu \mathrm{m}$ diâm., ou alongados, 21,25-22,5×17,5-15 $\mu$ m; 1-2 por oogônio.

Material examinado: BRASIL. São Paulo: Santo André, Reserva Biológica de Paranapiacaba, amostra de solo, 2346'53"S e 46¹8'69'"W, 18/XI/2004, A.L. Gomes (SPC 2000).

As características dos espécimes isolados estão de acordo com Seymour (1970) e Rocha \& Pires-Zottarelli (2002). Os zoósporos encistados e os oogônios piriformes dos espécimes descritos por Pires-Zottarelli et al. (1996) apresentaram-se maiores, com 13-22 um e 28-44×27-33 $\mu \mathrm{m}$, respectivamente. A espécie foi isolada pela primeira vez no Brasil por Pires-Zottarelli et al. (1996), de amostras de água do Parque Estadual das Fontes do Ipiranga, São Paulo. Esta é a primeira citação para a Reserva.

O presente estudo contribuiu para a ampliação do conhecimento da ocorrência e distribuição dos oomicetos de áreas de Mata Atlântica do Estado de São Paulo e do país. Dos táxons isolados no presente estudo, $60 \%$ das espécies são primeira citação para a Reserva, 9\% para o Estado de São Paulo e 20\% para o Brasil. O restante das espécies, que somam 11\%, já possuíam relatos anteriores. 


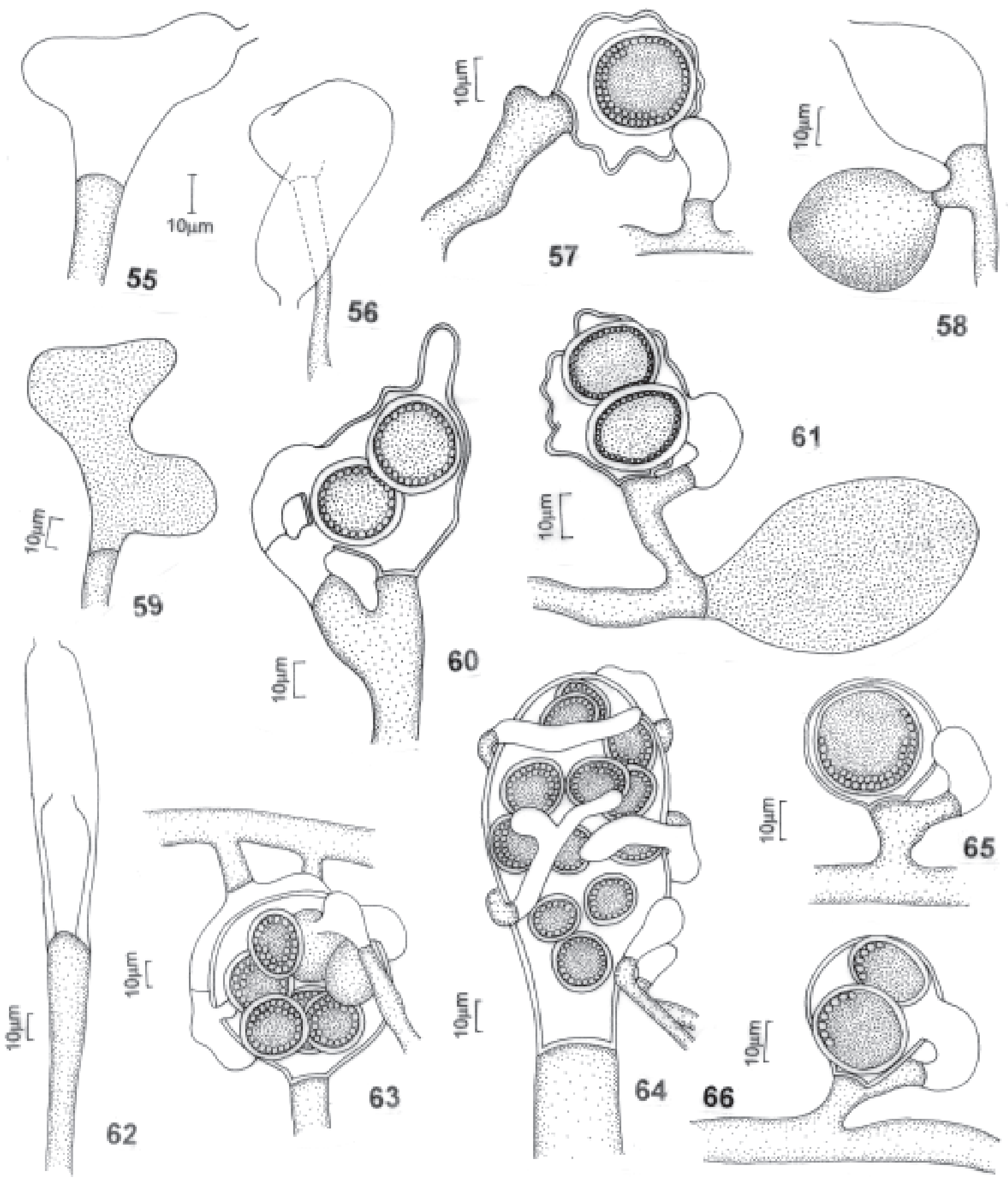

Figuras 55-66. 55-58. Pythiopsis humphreyana Coker. 55-56. Zoosporângios irregulares. 57.Oogônio com papilas, oósporo subcêntrico e anterídio diclino. 58. Zoosporângio e gema. 59-61. P. irregularis Seymour. 59. Zoosporângio irregular. 60-61. Oogônios com anterídios andróginos e oósporos cêntricos. 62-64. Saprolegnia diclina Humphrey. 62. Zoosporângio com proliferação interna. 63-64. Oogônios com oósporos cêntricos e subcêntricos, e anterídios díclinos e monóclinos. 65-66. S. subterranea (Dissman) Seymour. Oogônios com anterídios andróginos e oósporos subexcêntricos. 


\section{Agradecimentos}

Ao $\mathrm{CNPq}$, pela bolsa de mestrado concedida à primeira autora e produtividade à segunda; à Fapesp, pelo auxílio financeiro; ao Instituto de Botânica de São Paulo, pela infra-estrutura para o desenvolvimento do trabalho.

\section{Literatura citada}

Alexopoulos, C.J.; Mims, C.W. \& Blackwell, M. 1996. Introductory Mycology. New York, John Wiley \& Sons.

Antunes, M.F.R.; Ninomiya, A. \& Schoenlein-Crusius, I.H. 1993. Efeitos da queimada sobre a micota de solo de mata atlântica na Reserva Biológica do Alto da Serra de Paranapiacaba, SP. Hoehnea 20: 1-8.

Baptista, F.R.; Pires-Zottarelli, C.L.A.; Rocha, M. \& Milanez, A.I. 2004. The genus Pythium Pringsheim from Brazilian cerrado areas, in the state of São Paulo, Brazil. Revista Brasileira de Botânica 27: 281-290.

Beneke, E.S. \& Rogers, A.L. 1962. Aquatic Phycomycetes isolated in the states of Minas Gerais, São Paulo, and Paraná, Brazil. Rickia 1: 181-193.

Carvalho, I. \& Milanez, A.I. 1989. Efeitos da temperatura e umidade do solo sobre Pythium splendens. Revista de Microbiologia 20: 477-482.

Dick, M.W. 1989. Phytophthora undulata comb. nov. Mycotaxon 35: 449-453.

Figueiredo, M.B. \& Pimentel, C.P.V. 1975. Métodos utilizados para conservação de fungos na Micoteca da Seção de Micologia Fitopatológica do Instituto Biológico. Summa Phytopathologica 1: 299-302.

Frezzi, M.J. 1956. Especies de Pythium fitopatógenas identificadas en la República Argentina. Revista de Investigaciones Agricolas 10: 113-241.

Goldie-Smith, E.K. 1952. The sporangial phase of Pythium undulatum Petersen. Journal of the Elisha Mitchell Scientific Society 68: 273-292.

Gomes, A.L. \& Pires-Zottarelli, C.L.A. 2006. Diversidade de Oomycota da reserva Biológica de Paranapiacaba, Santo André, SP: primeiras citações para o Brasil. Revista Brasileira de Botânica 29: 569-577.

Gomes, A.L.; Pires-Zottarelli, C.L.A.; Rocha, M. \& Milanez, A.I. 2003. Saprolegniaceae de áreas de cerrado do Estado de São Paulo, SP. Hoehnea 30: 95-110.

Hunneycutt, M.B. 1952. A new water mold on keratinized materials. Journal of the Elisha Mitchell Scientific Society 68: 109-112.

Johnson Jr., T.W. 1956. The genus Achlya: morphology and taxonomy. Ann Arbor, University of Michigan Press.

Johnson Jr., T.W.; Seymour, R.L. \& Padgett, D.E. 2005. Systematics of the Saprolegniaceae: New taxa. Mycotaxon 92: 1-10.

Johnson Jr., T.W.; Seymour, R.L. \& Padgett, D.E. 2002. Biology and systematics of Saprolegniaceae. Disponível em > www.uncw.edu/people/padgett/book. (Acesso em: novembro/2002).

Karling, J.S. 1944. Brazilian chytrids. IV. Species of Rozella. Mycologia 36: 638-647.
Kirk, P.M.; Cannon, P.F.; David, J.C. \& Stalpers, J.A. 2001. Dictionary of Fungi. Wallingford, CABI Bioscience.

Milanez, A.I. 1969. Occurrence of Achlya radiosa in the Americas. Rickia 4: 41-46.

Milanez, A.I. 1970. Contributions to the knowledge of Aquatic Phycomycetes of São Paulo State. I. Oomycetes from the west region. Rickia 5: 23-43.

Milanez, A.I. 1989. Fungos de águas continentais. In: O. Fidalgo \& V.L. Bononi (coords.). Técnicas de coleta, preservação e herborização de material botânico. Série Documentos. São Paulo, Instituto de Botânica.

Milanez, A.I. \& Trufem, S.F.B. 1984. Fungos zoospóricos em frutos submersos do Parque Estadual das Fontes do Ipiranga, São Paulo, II. Rickia 11: 77-84.

Milanez, A.I.; Pires-Zottarelli, C.L.A. \& Schoenlein-Crusius, I.H. 1994. Fungos aquáticos da região de Mata Atlântica do Estado de São Paulo. Pp. 142-149. In: Anais do III Simpósio de Ecossistemas Brasileiros da Costa Brasileira. v.2. São Paulo, ACIESP.

Milanez, A.I.; Pires-Zottarelli, C.L.A. \& Schoenlein-Crusius, I.H. 1996. Criptógamos do Parque Estadual das Fontes do Ipiranga, São Paulo, SP. Fungos, 5: Leptomitales (Rhipidiaceae). Hoehnea 23: 67-76.

Pires-Zottarelli, C.L.A. \& Milanez, A.I. 1993. Fungos zoospóricos da "Represa do Lobo" ("Broa"). Novas citações para o Brasil. Revista Brasileira de Botânica 16: 205-220.

Pires-Zottarelli, C.L.A.; Schoenlein-Crusius, I.H. \& Milanez, A.I. 1993. Quantitative estimation of zoosporic fungi and aquatic hyphomycetes on leaves submerged in a stream in the Atlantic rainforest, in the State of São Paulo, Brazil. Revista de Microbiologia 24: 192-197.

Pires-Zottarelli, C.L.A.; Milanez, A.I.; Schoenlein-Crusius, I.H. \& Lohmann, L.G. 1996. Criptógamos do Parque Estadual das Fontes do Ipiranga, São Paulo, SP. Fungos, 4: Saprolegniales. Hoehnea 23: 39-66.

Plaats-Niterink, A.J. van der. 1981. Monograph of genus Pythium. Studies in Mycology 21: 1-242.

Rocha, M. \& Pires-Zottarelli, C.L.A. 2002. Chytridiomycota e Oomycota da Represa do Guarapiranga, São Paulo, SP. Acta Botanica Brasilica 16: 287-309.

Rogers, A.L.; Milanez, A.I. \& Beneke, E.S. 1970. Additional aquatic fungi from São Paulo State. Rickia 5: 93-110.

Schoenlein-Crusius, I.H. \& Milanez, A.I. 1998. Fungos zoospóricos (Mastigomycotina) da mata atlântica da Reserva Biológica do Alto da Serra de Paranapiacaba, município de Santo André, SP. Revista Brasileira de Botânica 21: 177-181.

Schoenlein-Crusius, I.H.; Pires-Zottarelli, C.L.A. \& Milanez, A.I. 1992. Aquatic fungi in leaves submerged in a stream in the Atlantic rainforest. Revista de Microbiologia 23: 167-171.

Schoenlein-Crusius, I.H.; Pires-Zottarelli, C.L.A.; Milanez, A.I. \& Humphreys, R.D. 1998. Influence of nutrients concentration on the aquatic mycota of leaves submerged in a stream in the Atlantic rainforest. Verhandlungen der Internationalen Vereinigung für Limnologie 26: 1125-1128. 
Schoenlein-Crusius, I.H.; Pires-Zottarelli, C.L.A. \& Milanez, A.I. 1999. Interaction between the mineral content and the occurrence number of aquatic fungi in leaves submerged in a stream in the Atlantic rainforest, São Paulo, Brazil. Revista Brasileira de Botânica 22: 133-139.

Schoenlein-Crusius, I.H.; Milanez, A.I.; Trufem, S.F.B.; PiresZottarelli, C.L.A.; Grandi, R.A.P.; Santos, M.L. \& Giustra, K.C. 2006. Microscopic fungi in the Atlantic Rainforest in Cubatão, São Paulo, Brazil. Brazilian Journal of Microbiology 37: 244-252.
Scott, W.W. 1961. A revision of the genus Aphanomyces. Technical Bulletin Virginia Agricultural Experiment Station 151: 1-95.

Seymour, R.L. 1970. The genus Saprolegnia. Nova Hedwigia 19: $1-124$.

Sparrow Jr., F.K. 1960. Aquatic Phycomycetes. Ann Arbor, University of Michigan Press.

Upadhyay, H.P. 1967. Soil fungi from the North-east Brazil. III. Phycomycetes. Mycopathologia et Mycologia Applicata 31: 49-61. 